\title{
A PHYLOGENETIC STUDY OF THE VISCERAL AF- FERENT AREAS ASSOCIATED WITH THE FACIAL, GLOSSOPHARYNGEAL, AND VAGUS NERVES, AND THEIR FIBER CONNECTIONS. THE EFFERENT FACTAL NUCLEUS
}

\author{
JOHN WALTER BARNARD \\ Laboratory of Comparative Neurology, Department of Anatomy, \\ University of Michigan ${ }^{2}$ \\ TWENTY-FOUR FIGURES
}

(Accepted for publication September 21, 1935)



${ }^{1}$ A dissertation submitted in partial fulfilment of the requirements of the degree of doctor of philosophy. 


\section{INTRODUCTION}

The following account deals with the phylogenetic development of the visceral afferent systems of the brain stem. The visceral afferent centers and their connections are considered in a series of vertebrates from cyclostomes through mammals. The efferent facial nucleus has been considered because of its changes in position, which illustrate so well the rise and fall of the visceral afferent systems throughout the vertebrate series.

The material used in the preparation of this paper is part of the Huber Neurological Collection of the Laboratory of Comparative Neurology, Department of Anatomy, University of Michigan, and consists of brains cut serially in transverse, frontal, and sagittal planes and stained by the Huber ('27) modification of the toluidin blue method or prepared by pyridine silver methods (Huber and Guild, '13). Several Weigert series were available for comparison.

I am deeply grateful to have had the opportunity to work under the late Dean Huber and I also wish to thank Prof. Elizabeth Crosby for her kindness and for her untiring efforts on my behalf in the preparation of this paper.

DESCRIPTION OF THE MATERIAL STUDIED

1. Petromyzonts (Entosphenus appendix and Ichthyomyzon concolor)

\section{A. The nuclear groups}

1. The visceral afferent gray associated with the facial, glossopharyngeal and vagus nerves (figs. 1, 3). These centers are very generalized in petromyzonts. The vagal lobe (fig. 3 ) extends through the regions of the glossopharyngeal and vagus nerves. Cephalic to the lobe there exists only the very primitive visceral afferent periventricular gray (fig. 1), a narrow band of small, closely packed cells which are from round to spindle-shaped in outline. It extends from the sulcus limitans, along the medial aspect of the nucleus medialis (fig. 1) of the 
acustico-lateral area, to a point about halfway between the sulcus limitans and the dorsal tip of the acustico-lateral area. Medially it is bounded by the ependyme of the fourth ventricle and laterally by the caudally running visceral afferent facial root and the ventrally running fibers (fig. 1) from the acusticolateral area and the cerebellum. In the midregion of the efferent trigeminal nucleus, the visceral afferent gray begins to pass insensibly into cerebellar gray. Just cephalic to the plane

\section{ABBREVIATIONS FOR ALL FIGURES}

ar.ac, area acustica ar.ac.lat., area acustico-lateralis ar.fun., area funicularis ar.vest., area vestibularis c, nucleus cerebelli lateralis of Edinger c.c., canalis centralis

cer., cerebellum

c.mam., corpus mamillare

c.mot.teg., motor tegmental cells

c.Mull., Müller cell

col.inf., collieulus inferior

com.ans., commissura ansulata

com.cer., commissura cerebelli

com.mes., commissura mesencephali

com.s., commissura somatica

com.v., commissura viseeralis

cr.cer., erista cerebellaris

dec.teg., decussatio tegmenti

deep v.af.r.N.X., deep visceral afferent root of the vagus nerve

em.subcer.teg., eminentia subcerebellaris tegmenti

fib.arc., fibrae arcuatae

fib.cer.mot., fibrae cerebello-motoriae

fib.com.cer., fibrae commissurae cerebelli

fib.lem.ac.lat., fibrae lemnisei acusticolateralis

fib.s., fibrae somaticae

fib.tr.gust.sec.a.VII, fibrae tractus gustatorii secundi ascendentis lobi facialis

fib.tr.gust.sec.a.X, fibrae tractus gustatorii secundi ascendentis lobi vagi

fib.v., fibrae viscerales

fib.visc.sec., fibrae viscerales secundae

f.l.m., fasciculus longitudinalis medialis f.sol., faseiculus solitarius

f.sol. + n., fascieulus solitarius et nucleus

gr.perivent., griseum periventriculare

gr.ret., griseum retieulare

hyp., hypothalamus

j., ventrally arising arcuates

$\mathbf{k}$, dorsally arising arcuates

l.aur., lobus aurieularis

lem.ac.lat., lemniscus acustico-lateralis

lem.bulb., lemniseus bulbaris

lem.med., lemniscus medialis

1.fac., lobus facialis

I.glos., lobus glossopharyngei

l.vag., lobus vagi

n.cer.lat., nucleus cerebellaris Iateralis (Edinger)

n.com.cer., nucleus commissurae cerebelli n.com.inf., nucleus commissurae infimae n.dor., nucleus dorsalis

n.f.sol., nucleus fasciculi solitarii

n.fun.lat., nucleus funicularis lateralis

n.fun.med., nueleus funicularis medialis

n.gust.sec., nucleus gustatorius secundus n.interc., nucleus intercalatus

n.interm., nucleus intermedius

n.isth., nucleus isthmi

n.isth.p.magnocell., nucleus isthmi pars magnocellularis

n.isth.p.parvocell., nucleus isthmi pars parvocellularis

n.lem.lat., nucleus lemnisci lateralis

n.med., nucleus medialis

n.med.C., median nucleus of Cajal

n.N.III, nucleus nervi oculomotorii

n.N.IV, nucleus nervi trochlearis 
n.N.XII, nucleus nervi hypoglossi n.parasol., nucleus parasolitarius n.ret.p.lat., nucleus reticularis pars lateralis

n.ret.p.med., nucleus reticularis pars medialis

n.vent., nueleus ventralis

n.visc.sec., nucleus visceralis secundus

N.IV, nervus trochlearis

N.VIII, nervus acusticus

ol.inf., oliva inferior

$p$, fibers of passage

pyr., pyramis

q, combined descending cervical bundles of Cajal

rad.d.N.V, radix descendens nervi trigemini

rad.d.N. $V+n$. radix descendens nervi trigemini et nucleus

rad.d.N.VIII, radix descendens nervi acustici

rad.N.lin.lat.ant., radix nervi lineae lateralis anterioris

rad.N.V, radix nervi trigemini

rad.N.XII, radix nervi hypoglossi

s.af.r.N.VII, somatic afferent root of the facial nerve

s.af.r.N.IX, somatic afferent root of the glossopharyngeal nerve

str.gran., stratum granulosum

superf.v.af.r.N.X, superficial visceral afferent root of the vagus nerve

$t$, vestibular portion of the fasciculus solitarius

tect., tectum

tr.bulb.cer., tractus bulbo-cerebellaris

tr.bulb.tect., tractus bulbo-tectalis

tr.bulb.tect.lat., tractus bulbo-tectalis lateralis

tr.cer.hyp., tractus cerebello-hypothalamicus

tr.gust.cer., tractus gustato-eerebellaris

tr.gust.hyp., tractus gustato-hypothalamicus

tr.gust.mam., tractus gustato-mamillaris

tr.gust.sec.a., tractus gustatorius seeundus ascendens

tr.gust.sec.a.VII, tractus gustatorius secundus ascendens lobi facialis
tr.gust.sec.a.VII-X, tractus gustatorius secundus ascendens lobi facialis et vagi

tr.gust.sec.a.X, tractus gustatorius secundus ascendens lobi vagi

tr.gust.sec.d.VII, tractus gustatorius secundus descendens lobi facialis

tr.gust.sec.d.VII-X, tractus gustatorius secundus descendens lobi facialis et vagi

tr.gust.sec.d.X, tractus gustatorius secundus descendens lobi vagi

tr.gust.valv., tractus gustato-valvulus

tr.lob.bulb., tractus lobo-bulbaris

tr.sp.cer., tractus spino-cerebellaris

tr.visc.aur., tractus viscero-auricularis

tr.visc.sec.a., tractus visceralis secundus ascendens

v.af.r.N.VII, visceral afferent root of the facial nerve

V.af.r.N.IX, visceral afferent root of the glossopharyngeal nerve

v.af.r.N.X, visceral afferent root of the vagus nerve

valv.cer., valvula cerebelli

v.ef.n.N.V, visceral efferent nucleus of the trigeminal nerve

v.ef.n.N.VII, visceral efferent nucleus of the facial nerve

v.ef.n.N.IX, visceral efferent nucleus of the glossopharyngeal nerve

v.ef.n.N.X, visceral efferent nucleus of the vagus nerve

v.ef.r.N.V, visceral efferent root of the trigeminal nerve

v.ef.r.N.VII, visceral efferent root of the facial nerve

v.ef.r.N.IX, visceral efferent root of the glossopharyngeal nerve

v.ef.r.N.X, visceral efferent root of the vagus nerve

v.op., ventriculus opticus

v.III, ventriculus tertius

v.IV, ventriculus quartus

$w$, cellular layers of the vagal lobe

$x$, small motor tegmental cells

$y$, dorsal descending cervical bundle

$z$, ventral descending cervical bundle 
of entrance of the root of the vagus nerve there is an increase in the number of the cells scattered throughout the body of the lobe.

The cephalic end of the combined vagal and glossopharyngeal lobe consists of the thickened periventricular gray, which is from two to three cells deep, and of the few scattered cells within the lobe. The periventricular gray extends from the sulcus limitans to almost the upper tip of the medulla oblongata, the lobe occupying the medial half of the entire dorsal region (fig. 3) on each side of the medulla oblongata. The periventricular gray runs only from the sulcus limitans to a



Fig. 1 A transverse section through the level of entrance of the facial nerve. The viseeral afferent component of this nerve is shown on the left side. Ichthyomyzon concolor. Chrome silver. $\times 28$.

point scarcely halfway to the dorsal tip of the lobe. In among its small cells are several very large cells. Caudal to the vagus nerve the two vagal lobes approach each other above the ventricle. There is no longer any periventricular gray. Here the lobes are larger and the cells of the lobe farther apart (fig. 14 a).

At the calamus scriptorius the lobes retain their identity. The periventricular gray begins to reappear, running from the sulcus limitans to the midline. Of this periventricular gray there are two layers, a deep, darkly staining layer of small cells and a superficial layer of scattered, medium-sized cells. The superficial group is thicker at the sulcus limitans than 
at the midline where it disappears. The deep layer runs dorsomedially from the sulcus limitans to the midline and, at the midline, turns dorsally so that, with its fellow of the opposite side, it separates the vagal lobes (fig. 14 a).

2. The nucleus of the inferior commissure of Haller (fig. 14 a). The cells of the inferior commissure may be divided into two types-those belonging to the median nucleus of Ramón y Cajal as reported by Johnston ('02) and those among the fibers of the vagal lobe. The small, darkly staining cells of the median nucleus represent the fusion of the periventricular gray. They fade out into the gray joining the two dorsal horns at the level of the spinal cord. Those cells among the fibers of the vagal lobe which continue back to the spinal cord are very few in number. They are medium sized and round to spindle-shaped cells that disappear at spinal cord levels. The periventricular gray merges into the dorsal horn gray proper and the gray connecting the two dorsal horns above the ventricle.

In general, as Johnston ('02) has pointed out, the inferior commissure and the calamus scriptorius are quite cephalic in this form. They are cephalic to the spinal cord proper to an appreciable extent. Also the inferior commissure is somewhat caudal to the calamus scriptorius which again is not the usual configuration.

3. The efferent facial nucleus (fig. 2). This nucleus is adjacent to the caudal end of the efferent trigeminal nucleus, from which it is separated by a large Müller cell (fig. 2) as has been reported by Tretjakoff ('09) and Addens ('33). Johnston ('02), Shilling ('07), Ariëns Kappers ('08, '10), Krause ('23) and Saito ('28) did not find this Müller cell. The 1936 edition of the Ariëns Kappers, Huber and Crosby text has it figured and described according to the interpretation of Tretjakoff and Addens. The separation between the efferent trigeminal and the efferent facial nuclei is in an oblique plane so that the medial portion of the cephalic end of the efferent facial nucleus is more caudal than the lateral portion (fig. 2). 
The cells of the efferent facial nucleus are smaller than those of the efferent trigeminal nucleus (figs. 1,2) although the caudal cells of the efferent trigeminal nucleus are somewhat smaller than those more cephalically placed. Tretjakoff ('09) found the efferent facial cells larger than the efferent trigeminal cells in Ammocoetes. In correspondence with the smaller size of the efferent facial nucleus and of its constituent neurons in Entosphenus and Ichthyomyzon, as compared with the sizes of the efferent trigeminal nucleus and its neurons in these forms, the facial nucleus produces less of a ventricular eminence than does the trigeminal nucleus.

Röthig and Ariëns Kappers ('14) and Jansen ('30) for Myxine, Black ('17) for Bdellostoma and Addens ('33) for both Myxine and Bdellostoma have emphasized the difficulty in distinguishing between the efferent trigeminal and the efferent facial nuclei. There is no Müller cell with its large dimensions to separate the two nuclei and the cells graduate in size from the large-celled efferent trigeminal nucleus to the small-celled efferent facial nucleus.

\section{B. The root fibers}

1. The visceral afferent roots of the facial, glossopharyngeal and vagus nerves (figs. 1,3 ). The visceral afferent facial root (fig. 1) enters the medulla oblongata with the ventral portion of the anterior lateral line nerve. Tretjakoff ('09) did not find the root in Ammocoetes, but Johnston ('02, '08) described it in petromyzonts. After entering the medulla oblongata the fibers swing medially through the ventral portion of the nucleus medialis of the acustico-lateral area to the medial aspect of this nucleus (fig. 1), where they turn sharply caudalward. Collaterals of the stem fibers are given off to end in the visceral afferent periventricular gray. In the region of the glossopharyngeal nerve the visceral afferent facial root begins to separate off from the caudally running fibers of the nucleus medialis of the acustico-lateral area, the latter fibers swinging laterally and dorsally while the facial fibers swing medially and dorsally into the substance of the vagal lobe. 
Here many of them end, while others continue caudally and lose their identity among the fibers of the lobe.

The visceral afferent glossopharyngeal root enters the medulla oblongata caudoventral to the posterior lateral line nerve, and so marks the cephalic limit of the combined glossopharyngeal and vagal lobe. The root courses medially and dorsally in an are and is lost among the ventrally running fibers of the acustico-lateral area as it nears the vagal lobe. Johnston ('02) described this root in a comparable manner.

The more cephalic vagus rootlets have the same course as found for that of the glossopharyngeal nerve. The caudal visceral afferent vagus rootlets (fig. 3 ) are traced, as Johnston ('02) stated, dorsally along the periphery with the crista cerebellaris fibers. At a point quite high in the acustico-lateral region, they filter across to the lateral aspect of the vagal lobe. The endings of these fibers cannot be determined, a great many of them probably running caudalward past the calamus scriptorius.

2. The efferent facial root (figs. 1, 2). The fibers leave the ventral aspect of their nucleus and turn sharply lateralward just ventral to their origin to lose themselves in the fine arcuate fibers of the acustico-lateral area and of the cerebellum that are swinging down toward the midline. They course cephalolaterally among these arcuates and cannot be distinguished therefrom in transverse material. At the level of the Müller cell which separates the efferent nuclei of the trigeminal and facial nerves, the small efferent facial root leaves the arcuates in which it is immersed and dips ventrolaterally through the dorsolateral corner of the descending trigeminal root (fig. 1) and then out along the lateral aspect of this descending root to the edge of the medulla oblongata. In an obliquely cut frontal series the root is seen to arise only from the efferent facial nucleus; i.e., from the cells caudal and lateral to the large Müller cell (fig. 2). Tretjakoff ('09) and Johnston ('02) described two efferent facial roots, although only one is found in the material studied for this account. The positions of the efferent facial nucleus and its root are fully discussed by Ariëns Kappers ('08) and Addens ('33). 
C. The fiber connections

1. The secondary connections of the gray associated with the visceral afferent roots of the facial, glossopharyngeal and vagus nerves (figs. 1,3 ). The primitive state of the brain of petromyzonts suggests that these should be comparatively simple. Thus the largest connection is that to the adjacent visceral efferent nuclei of the trigeminal, facial, glossopharyngeal, and vagus nerves. The fibers pass to the efferent



Fig. 2 A frontal section through the Müller cell which separates the efferent facial nucleus from the efferent trigeminal nucleus. Only a small part of the Müller cell shows in the section. Entosphenus appendix. Chrome silver. $\times 28$.

nuclei by joining the acustico-lateral-motorius and cerebellomotorius fibers (fig. 1) which sweep down from their more dorsal origins along the lateral border of the visceral afferent gray, around the sulcus limitans, to end in the dendritic bed between the respective efferent nuclei and the fourth ventricle (fig. 3).

Passing slightly more lateral to the fibers just described is a larger bundle from the acustico-lateral area (fig. 1) and, in the regions of the facial and trigeminal nerves, from the cerebellum, which swings ventrally and medially around the sulcus limitans and passes ventral to the visceral efferent column 
toward the midline. Fibers from the visceral afferent area join this system. As they pass medially they give off collaterals which run dorsally between the cells of the visceral efferent nuclei to join the dendritic bed above the cells. The remaining fibers go on toward the midline. The bundle divides, some fibers running straight to the midline and into relationship with the efferent nuclei of the opposite side, the rest turning ventrally and coursing ventromedially until almost at the midline, where they turn sharply medially and eross. Beyond the midline they turn somewhat cephalically and run out to the bulbo-cerebellar tract and the bulbar lemniscus system



Fig. 3 A transverse section through the vagal lobe showing a visceral afferent root of the vagus nerve. Ichthyomyzon concolor. Chrome silver. $\times 28$.

(the bulbo-tectal tract, figs. 1,3). Still other fibers run to the periphery at the raphé and on around to the erista cerebellaris of the opposite side. Cephalic to the facial root the bulbotectal tract is situated just medial to the descending trigeminal root and dorsal to the tecto-bulbar tract. The bulbar lemniscus may be traced into the midbrain, to both tectal and tegmental regions. The combined spino-cerebellar and bulbo-cerebellar tract is medial to the tecto-bulbar tract and is seen as an elongated oval mass with its main axis horizontally placed. In the region of the vagus nerve this tract receives many more visceral fibers than it does more cephalically. At these caudal levels it is situated slightly lateral to the midline (fig. 3). 
Johnston ('02) has mentioned these visceral arcuates but did not trace the bulbo-tectal tract into the tectum.

There is no differentiated, uncrossed secondary gustatory tract in the lamprey. All connections with higher centers are through the bulbar lemniscus system.

2. The inferior commissure of Haller (fig. 14 a). Fibers of the acustico-lateral area and the vagal lobe are not differentiated at the inferior commissure except that the acustic fibers are more dorsal and fewer in number. The amount of visceral crossing is less near the cephalic end of the inferior commissure than more caudalward. After crossing, the fibers course around the dorsolateral aspect of the ventricle, some continuing on around to the caudal end of the efferent vagus nucleus; some turn out into the acustico-lateral area, while others, running close to the ependyme, course down to the midline, giving off collaterals to the efferent centers of the region.

Vagal lobe fibers, probably mostly uncrossed, continue on back into the cord as a quite prominent bundle just dorsal to the spinal cord gray. This bundle may be followed, as far caudalward as the material studied extends, as a still prominent bundle even though becoming smaller. Fibers continue to cross as the bundle courses caudally. Its connections are sparse and to the adjoining spinal cord gray. At cephalic levels of the spinal cord, fibers, which constitute a somatic commissure, interconnect the dorsal horn regions.

3. The tracts entering the efferent facial nucleus. The fiber connections to the efferent facial nucleus are of a very general and primitive type. The most noticeable place of synapse for the efferent cells is in the dendritic bed above the nucleus, between it and the ependyme of the fourth ventricle. This dendritic bed swings around the limiting sulcus and gradually disappears between the ependyme and the visceral afferent area. Fibers from the acustico-lateral area and the cerebellum swing ventrally to join this bed of dendrites. The medial boundary of the dendritic bed above the efferent nucleus is continuous at the midline with arcuates coming from the opposite side. There are also the more laterally running 
bundles which contain fibers from the visceral afferent area and the acustico-lateral area. Another connection observed is that of the small fine dendrites of the efferent cells of the facial nucleus that run ventrally from the dendritic bed between the cells of the efferent nucleus and out into the ventral field of white matter, there making connections with collaterals from the major descending systems.

\section{Ganoid (Amia calva)}

\section{A. The nuclear groups}

1. The visceral afferent gray associated with the facial, glossopharyngeal and vagus nerves. This gray is separable into three divisions, the facial, glossopharyngeal and vagal lobes. These lobes are continuous with one another so that their boundary lines are difficult to establish. The best criterion is the level of termination of the root fibers within the visceral afferent area. Thus the region between the facial and glossopharyngeal roots is the facial lobe; between the glossopharyngeal and the first vagus rootlet is the glossopharyngeal lobe; and between the first vagus rootlet and the inferior commissure of Haller is the vagal lobe.

The facial lobe is a low protuberance of the lateral wall into the fourth ventricle, between the sulcus limitans and the crista cerebellaris. Its dorsolateral, lateral, and ventrolateral boundaries are the acustico-lateral area, from which it is separated by arcuate fibers that are sweeping down toward the midline. The glossopharyngeal lobe projects farther into the ventricle than does the facial lobe so that the acustico-lateral area borders only the lateral surface of the glossopharyngeal lobe. The crista cerebellaris overhangs this lobe, from which it is separated by a deep fissure. The vagal lobe is similar to the glossopharyngeal. Near its caudal end the crista cerebellaris disappears and the vagal lobe is covered on its dorsal surface only by a small part of the acustico-lateral area. The lobe projects less into the ventricle, having a greater dorsoventral extent (fig. 5). 
At the level of entrance of the visceral afferent facial root into the facial lobe the configuration of the lobe is different than at any other level. The cells are all forced into the ventromedial corner of the lobe while the large root swings in at its dorsolateral border. The longitudinally running bundles of the acustico-lateral area are forced to the ventrolateral and dorsolateral aspects of the facial lobe. The outgoing fibers of the facial lobe are leaving at the ventromedial corner of the lobe around the sulcus limitans. In the cellular region the cells are large and spindle-shaped. Their long axes are oriented in a ventrolateral direction, corresponding to the direction of the outgoing fibers of the lobe. Caudal to the incoming visceral afferent facial root the lobe becomes infiltrated with small granule cells and large spindle-shaped cells which are spread throughout the lobe so that the root is broken up into smaller fascicles. In the region midway between the facial and glossopharyngeal nerves the cells are less numerous and there are fewer transversely running fibers breaking up the fascicular pattern. The spindle-shaped cells still present no longer have any particular orientation.

The entrance of the visceral afferent glossopharyngeal root causes an increase in the number of both the spindleshaped and the small granule cells in the visceral afferent area. The root does not break up the general fascicular pattern of the lobe, since it is much smaller than that of the facial nerve. The cells do not organize but keep their general distribution. Caudal to the visceral afferent glossopharyngeal root the cells decrease somewhat in number but do not become as few as in the region cephalic to the root.

The entrance of the first visceral afferent vagus rootlet (fig. 5) into the vagal lobe is not far caudal to the level of entrance of the glossopharyngeal nerve. Like the visceral afferent glossopharyngeal root, it does not completely upset the general fascicular pattern of the lobe. The cells increase somewhat in number and by this increase the fibrous fasciculi become smaller. In the vagal lobe near the area of the sulcus limitans there is a group of large cells which are somewhat thick and spindle-shaped. 
They lie in about two rows parallel to the ventricular wall. Their position would indicate that they are the cell bodies of the longer secondary neurons which will go to the secondary gustatory tract and perhaps to the efferent vagus nucleus. The situation here is similar to that at the region of entrance of the visceral afferent facial root except that in the vagal lobe the cells are spread out more and seem to encircle the sulcus limitans somewhat. This appears to represent an early attempt at the sensory center specialization which gains its fullest expression in the highly gustatory teleosts.

Holmgren and van der Horst ('25) found a less specialized visceral afferent area for Ceratodus and also a much smaller one. Johnston's ('01) account of this area in Acipenser does not differ materially from the present description. Hocke Hoogenboom ('29) gave no detailed description of this portion of the nervous system of Polyodon.

2. The nucleus of the inferior commissure of Haller (fig. $14 \mathrm{~b})$. The cephalic end of the inferior commissure is composed of longitudinally running fibers not bound into bundles. These small fascicles are interspersed with many small granule cells and a few larger spindle-shaped cells comprising the nucleus of the inferior commissure. In this region of transition between the medulla oblongata and the spinal cord the paired portion of the inferior commissural nucleus, which is the caudal extension of the vagal lobe, begins to disappear so that just caudal to the calamus scriptorius it scarcely projects into the ventricle. Dorsolaterally the nucleus of the inferior commissure is bounded by the lateral funicular nucleus, dorsomedially by the fibers of the inferior commissure, and ventrally and medially by the fourth ventricle. Followed back through the planes of decussation of the inferior commissural fibers the nucleus of the commissure forms a small projection into the roof of the ventricle on each side of the midline (fig. $14 \mathrm{~b}$ ). In these small protuberances the cells are most numerous, although there are cells scattered throughout the entire commissural region. The cells are found to be medium and small-sized, the former dominating the field, 
The unpaired group of cells near the midline corresponds to the median nucleus of Ramón y Cajal, while the paired group of cells might be called the lateral nucleus of the inferior commissure.

3. The secondary gustatory nucleus (fig. 4). The caudal end of the nucleus is fused with the lateral cerebellar nucleus of Edinger. The most caudal end of these combined nuclei is a short distance cephalic to the trigeminal root, close to the fourth ventricle and just dorsal to the sulcus limitans.



Fig. 4 A transverse section through the middle of the secondary gustatory nucleus giving its relationship to the lateral cerebellar nucleus of Edinger. Amia calva. Toluidin blue, $\times 35$.

It is bounded laterally by the nucleus isthmi, as described by Holmgren and van der Horst ('25). More cephalically the dorsal tip of the cell mass differentiates as the lateral cerebellar nucleus of Edinger. This nucleus becomes quite dense and larger than the secondary gustatory nucleus (fig. 4). The secondary gustatory nucleus is bounded laterally by the superior cerebellar peduncle, and medially and ventrally by the fourth ventricle. The cells of the nucleus are triangular or spindle-shaped with their long axes pointed dorsolaterally. The cells are lined up parallel to the ventricle with their long axes perpendicular to the ventricle, illustrating their recent 
evolution from the condition of periventricular gray. More cephalically still the lateral cerebellar nucleus fades out and the forward end of the secondary gustatory nucleus dips down somewhat below the sulcus limitans. It is also shifted somewhat laterally.

4. The efferent facial nucleus. This mass consists of large, typically efferent cells with their dendrites oriented ventrally and somewhat laterally. The cells bodies are close to the floor of the ventricle between the sulcus limitans and the medial longitudinal fasciculus. The nucleus is found at the cephalic end of the posterior visceral efferent column. It forms the largest part of this column, there being more cells here than at any other region. The cephalic end is found midway between the levels of the roots of the facial and glossopharyngeal nerves. The caudal limit is just behind the level of entrance of the glossopharyngeal root. No anterior efferent nucleus of the facial nerve has been found. Holmgren and van der Horst ('25) for Ceratodus, Johnston ('01) for Acipenser and van der Horst for Chimaera ('18) did find such an anterior efferent facial nucleus. Droogleever Fortuyn ('12) found only one efferent facial nucleus in his Amia material and that was situated, as in this material, at the cephalic end of the posterior visceral efferent column. Theunissen ('14) found this latter configuration in Acipenser ruthenus and in Lepidosteus osseus, as did Hocke Hoogenboom ('29) in Polyodon.

\section{B. The root fibers}

1. The visceral afferent roots of the facial, glossopharyngeal and vagus nerves (fig. 5). The large visceral afferent facial root enters the medulla oblongata as the most cephalic and dorsal portion of the acustico-facial root complex. Inside the medulla oblongata it swings dorsally, medially and caudally in an arc to the cephalic end of the facial lobe. It enters the facial lobe on the latter's dorsolateral aspect and in so doing pushes the longitudinal bundles of the acustico-lateral area (which cephalic to the facial lobe fill the latter's place) ventrolaterally and dorsolaterally. The root breaks up immediately 
upon entry into smaller fascicles. Many fibers end at the level of entrance on the cells of the lobe. The transversely running bundles turn caudally. No evidence is found for a cephalic continuation of the facial lobe ahead of the root's entrance. The visceral afferent glossopharyngeal root enters the glossopharyngeal lobe on the latter's lateral aspect. It turns caudally and breaks up in the lobe. In sagittal material all visceral afferent root fibers turn caudally, although some end on the cells of the lobe very close to the level of entrance of



Fig. 5 A transverse section through the cephalic portion of the vagal lobe figuring its main connections. Amia calva. Chrome silver. $\times 22$.

their root. Some fibers of the first visceral afferent vagus rootlet (fig. 5) appear to pass directly to the cells of the efferent vagus nucleus. Otherwise the visceral afferent vagus rootlets end in the vagal lobe as does the visceral afferent glossopharyngeal root in the glossopharyngeal lobe.

2. The efferent facial root. The neuraxes of the cells of the efferent facial nucleus run dorsomedially from this nucleus to the floor of the fourth ventricle, forming a bundle on the dorsolateral aspect of the medial longitudinal fasciculus and projecting into the ventricle a little to each side of the midline. 
The fibers run cephalically to their genu where they turn sharply lateralward. At the sulcus limitans they turn somewhat ventrally and course ventrolaterally through the most caudal cells of the anterior visceral efferent column or the area included by van Hoevell in the efferent trigeminal nucleus. In searching for an anterior efferent facial nucleus this relationship with the efferent trigeminal nucleus was closely studied. In the material studied there is no evidence that fibers from this trigeminal nucleus join the efferent facial root. The root courses to the periphery of the medulla oblongata along the cephaloventral aspect of the acustic nerve.

\section{The fiber connections}

1. The secondary connections of the gray associated with the visceral afferent roots of the facial, glossopharyngeal and vagus nerves (fig. 5). Secondary fibers sweep out of the ventromedial angle of the visceral afferent centers around the sulcus limitans and end on the cells of the visceral efferent column. There seems no doubt but that some of these fibers sweep ventral to the efferent nuclei, across to the midline as arcuates and from thence to the efferent nuclei of the opposite side (fig. 5). The secondary ascending gustatory tract is but vaguely defined as a somewhat lighter area medial and dorsal to the descending trigeminal root. It is formed by fibers which filter out to this general area from the ventromedial corner of the visceral afferent centers (fig. 5). At no point is either the tract or its contributions from the visceral afferent area as definite as in higher fishes. Going cephalically the secondary gustatory tract retains its relationship to the descending trigeminal root until the latter is at the trigeminal root level, where it swings dorsally and medially to end in the secondary gustatory nucleus (fig. 4). The fibers are intermingled with the bulbo- and spino-cerebellar fascicles, many of which end on the lateral cerebellar nucleus which is in very close relationship to the secondary gustatory nucleus.

There are other fibers coming from the visceral afferent centers which take either one of two courses (fig. 5). They 
all join with the fibers sweeping down from the acusticolateral area and pass with them medially along the floor of the fourth ventricle. As the fibers pass dorsal to the visceral efferent column collaterals are given off which run in among the efferent cells. As the combined bundle reaches the lateral aspect of the medial longitudinal fasciculus, many of the fibers swing to the midline dorsal to, and through, the medial longitudinal fasciculus. At the midline these fibers turn ventrally and in the midregion of the raphe turn laterally. They run out to the area just medial to the secondary gustatory tract where they turn into the ascending fibers of the bulbar lemniscus system. On the way out to the bulbar lemniscus area some of the fibers pass into the medial reticular nucleus where they may end.

The other possible course for fibers leaving the visceral afferent centers is to run out ventrolaterally along with the small bundles which pass to the secondary gustatory tract. As the area of the secondary gustatory tract is approached the fibers turn ventromedially and then medially to run through the ventral field toward the midline. At the raphe they cross and join those fibers which are coming down from the medial longitudinal fasciculus region and with them swing out to the bulbar lemniscus. Thus there is, in Amia, as in the trout and the carp, a bulbar lemniscus system that receives fibers from the visceral afferent centers, although this bulbo-tectal tract is as primitive and as poorly defined as in petromyzonts. The extent of the system which contains connections from the visceral afferent area is from the region of the facial nerve back to the calamus scriptorius. The secondary descending gustatory tract of Herrick ('05) cannot be found in the available material.

2. The inferior commissure of Haller (fig. 14 b). The visceral portion of the inferior commissure is, in general, dorsal and cephalic to the somatic portion, although there are a few fibers of the latter that cross at all levels (even including the most cephalic levels). Many of the fibers that cross at the same level as the visceral commissure represent connections between the lateral funicular nucleus and the nucleus 
of the inferior commissure. The descending cervical bundles of Ramón y Cajal are similar to those found by Johnston ('01) in Acipenser. In the material available for study a medial and a lateral bundle, both of which are partially crossed, are found. Followed caudally the lateral bundle moves ventrally to lie just ventral to the medial bundle. At typical spinal cord levels these bundles begin to fade out, the lateral doing so before the medial. The bundles never leave the raphe region, as Johnston found they did in Acipenser ('01), but remain in among the dorsoventrally running fibers of the dorsal commissure of the cord. As the bundles fade out, their fibers turn ventrally and run to the dorsal commissure of the spinal cord where they pass to the gray of the dorsal horn regions. Thus the visceral afferent system of the medulla oblongata may exercise its influence over the somatic musculature of the spinal cord.

3. The fiber connections of the secondary gustatory nucleus (fig. 4). The first is a commissural connection between the two nuclei. It is quite small and diffuse so that no one clear group of fibers can be called gustatory, particularly since the commissural region contains a great many crossing cerebellar fibers. A tract which stands out but poorly is Herrick's tertiary gustatory tract to the hypothalamus. In sagitta] material it can be seen passing from the nucleus toward the hypothalamic region. It runs along with, and is not separable from, the cerebello-lobar tract, though it can be assigned to the ventral portion of this field. Johnston ('01, Acipenser), Holmgren and van der Horst ('25, Ceratodus) and Hocke Hoogenboom ('29, Polyodon) did not find this connection. A third connection may be provided with the tectum. Fascicles accompanying the cerebello-tectal tract swing into the region of the secondary gustatory nucleus, where they appear to end. Johnston ('01) described this connection, and Brickner ('30) found a gustato-tectal connection in several teleosts. At the cephalic end of the nucleus there is a connection to the midline region around the sulcus limitans. These fascicles run with the fibers from the cerebellum, these latter being cerebello-motorius and cerebello-tegmentals. As the fibers from 
the cerebellum pass around and through the secondary gustatory nucleus they pick up a few fibers from this latter nucleus.

4. The tracts entering the efferent facial nucleus. As described above (p. 521) the arcuates of the bulbar and acusticolateral lemnisci give off fibers to the efferent facial nucleus. There are other fibers among these arcuates that pass to the efferent facial nucleus of the opposite side. They do so by passing out from the midline along the arcuates coming down from that opposite side to the efferent facial cells. This contralateral connection appears more plentiful in the caudal regions of the efferent facial nucleus.

Throughout the length of the nucleus its cells send very long dendrites ventrally and somewhat laterally in among the longitudinally running fibers of the ventral field. Here they come into relation with descending systems from the tectum and possibly other higher centers. There are also the shorter, longitudinally running fibers from other regions of the medulla oblongata with which the dendrites come into relationship. No dendrites can be traced into the medial longitudinal fasciculus. However, there is evidence that fibers do run out laterally from the medial longitudinal fasciculus and end in the efferent facial nucleus.

\section{Teleosts (Salmo and Cyprinoides carpio)}

A. The nuclear groups in the trout

1. The visceral afferent gray associated with the facial, glossopharyngeal and vagus nerves (fig. 6). This gray is situated along the ventricular wall between the sulcus limitans and the overhanging acustico-lateral area and cerebellum. In the region of the facial nerve there is little or no projection into the ventricle. In the regions of the glossopharyngeal and vagus nerves the visceral afferent area projects quite noticeably into the ventricle, justifying the term of lobe.

The facial lobe in the region of the visceral afferent facial root is quite primitive, being not much more than a thickening in the periventricular gray. The cells show no great specializa- 
tion, being more or less triangular and spindle-shaped in outline and of medium size. One end of the cell is oriented toward the incoming fibers while the other main process is oriented in the opposite direction. This means that the neurons ventral to the incoming fibers are oriented dorsoventrally. These ventral neurons represent the cells of origin of many of the secondary fibers which ramify out into the ventral and lateral field of nerve fibers. Cell bodies situated medial to the incoming root are oriented horizontally in cross section material. The cells dorsal to the root do not have this ordered arrangement, being quite scattered. Cephalic to the visceral afferent facial root the cell mass which is around the incoming root is lost and nothing is left but a thickening in the periventricular gray. There are no root fibers of the facial nerve ascending in this region, only the primitive and slightly thickened periventricular gray which extends to the region of the secondary gustatory nucleus.

Caudal to the facial nerve the lobe becomes larger. The result is that, in the region of the glossopharyngeal nerve, it is greatly increased in the dorsoventral direction and projects farther into the ventricle. The periventricular gray is somewhat thicker than in the region of the facial nerve. The longitudinally running bundles are larger and the cells which are scattered through the lobe are more numerous than in the region of the facial nerve. The cell type remains the same. The cell bodies of the secondary fibers are concentrated in the ventral portion of the lobe. The periventricular gray is also very thick in this ventromedial corner.

At the level of the first vagus rootlet the vagal lobe (fig. 6 ) becomes larger than the glossopharyngeal. There are large, longitudinally running bundles and many cells interspersed among them. The periventricular gray is more differentiated, being thin along the dorsomedial aspect of the nucleus and quite thick along the ventromedial aspect. The cells are still of the simple, unspecialized type. At the level of the caudal vagus rootlets the lobe is at its largest, there being a steady increase in size from the region of the facial nerve back to the 
calamus scriptorius. At this latter level the vagal lobe is the most dorsal and medial structure of the medulla oblongata. It projects into the ventricle more than at cephalic levels. The periventricular gray now separates from the ependyme, leaving a space between it and the ependyme which contains a few scattered cells. The layer is three to five cells thick and forms the dorsomedial, medial and ventromedial boundaries of the vagal lobe. The cells are deeply staining, short and spindle-shaped, with their dendrites directed toward the center of the lobe. The layer has a distinct corticoid lamination suggesting a specialization of the type characteristic of sensory centers. This attempt at lamination is much more evident in the trout than in Amia where it can scarcely be regarded as more than a beginning of specialization. The dorsolateral, ventrolateral and lateral boundaries of the lobe are less well defined, being bounded by the loosely organized medial funicular nucleus. Throughout the inner part of the lobe are scattered small clumps of triangular to spindle-shaped cells.

2. The nucleus of the inferior commissure of Haller (fig. $14 \mathrm{c})$. At the calamus scriptorius the two vagal lobes join above the ventricle. The medial corticoid layer breaks up and becomes the layer of cells which forms the lateral border of the raphe region. The cells lose their regular orientation. The medial funicular nuclei move medially toward the lateral aspect of the commissural nucleus. The nucleus of the inferior commissure is composed of the remains of the vagal lobes and a median group of cells which does not appear cephalic to the calamus scriptorius.

The paired portion of the nucleus of the inferior commissure becomes a part of the general gray of the commissure a short distance caudal to the calamus scriptorius and loses all trace of its double origin. The cells are of the same type as is found in the vagal lobes. They persist, in lessened numbers, caudal to the point of complete fusion of the vagal lobes. The cells intermingle somewhat with the median nucleus of the commissure. 
The median nucleus of Ramón y Cajal begins at the calamus scriptorius. It is an amorphous group of cells in the raphé region above and among the fibers of the inferior commissure. The cells are lightly staining and of granular appearance with a few intermingled triangular to spindle-shaped cells. These granule cells continue farther caudally than do those of the paired portion, becoming continuous with the funicular gray of the cord region and its dorsal commissure. The inferior commissural region in the trout, as in Amia, illustrates more or less of a balance between somatic and visceral components as compared with such components in highly gustatory teleosts as the carp, Ameiurus and Gadus (Herrick, '05, '06, '07), and Siluris glanis (Berkelbach van der Sprenkel, '15).

3. The secondary gustatory nucleus (fig. 7). The caudal end of the nucleus is oval and is situated at the level of emergence of the efferent trigeminal root. Medially it is bounded by the fourth ventricle, laterally by the acustico-lateral lemniscus and its cells, dorsally by the granule cells of the cerebellum and ventrally by the efferent trigeminal nucleus. The cells are triangular to spindle in shape, stain lightly, and are scattered sparsely throughout the nucleus. The most dorsal tip of the gray of this region is probably the caudal end of the lateral cerebellar nucleus of Edinger ('08) but it is inseparable from the secondary gustatory nucleus at this point.

At the midlevel of the secondary gustatory nucleus (fig. 7, left side) the arrangement is quite different. The cells now have organization, lining up in two layers parallel to the ventricle. These layers are somewhat different from each other, the dorsomedial layer having medium-sized, triangular to spindle-shaped cells, and the ventrolateral layer having large, spindle-shaped cells mixed in with medium-sized cells of the generalized triangular to spindle form. The processes of the outer layer of cells are oriented, in general, at right angles to the layer. Medial to the two layers the periventricular gray is quite thickened. Lateral to the layers there is an almost cell free area wherein longitudinal fibers course through the nucleus. Lateral and ventral to this acellular area-and 
forming the lateral and ventral borders of the nucleus-is an irregular and scattered row of cells chiefly of the mediumsized, spindle-shaped type, the processes of which are oriented at right angles to the boundary line of the nucleus. The dorsal boundary of the nucleus is the layer of large spindle cells of Edinger's lateral cerebellar nucleus. The medial boundary is the ependyme of the fourth ventricle.

More cephalically the two layers are lost and only an irregular layer remains. It has, in two sections, very large spindle-shaped cells, the processes of which are oriented ventrolaterally. At its cephalic end the nucleus is filled with longitudinally running bundles and scattered cells. The fibers are lateral and the cells medial. The ventral boundary is the lateral part of the medial reticular nucleus which is associated with the efferent trigeminal nucleus. The dorsal border is the lateral cerebellar nucleus, which at this level begins to decrease in size. The lateral border is formed by small, loosely arranged clusters of cells which are intercalated between small fiber bundles, the entire group being almost round. The processes of these cells are oriented perpendicularly to the border of the nucleus.

At the cephalic tip of the nucleus the layer of cells parallel to the ventricle dies out. The cells at the lateral boundary of the nucleus move ventrally and merge with the reticular cells below. The lateral cerebellar nucleus of Edinger fades out into the nucleus isthmi. The longitudinally running fibers, containing a few scattered cells, turn away toward their destination and only a slightly thickened periventricular gray is left.

The secondary gustatory nucleus is about the same size in the trout as in Amia but does not approach the dimensions of that nucleus in the highly gustatory fishes such as the carp and Ameiurus as described by Herrick ('05, '06). Burr ('28) did not find a secondary gustatory nucleus in his Orthagoriscus material.

4. The efferent facial nucleus. The nucleus is the most cephalic portion of the posterior visceral efferent column. It 
is the only nucleus from which efferent fibers of the facial nerve take origin. The cells are situated a short distance from the fourth ventricle just ventral to the sulcus limitans, and are large, typical multipolar efferent neurons. Their axons run dorsomedially while their dendrites ramify in all directions.

The efferent facial nucleus has its cephalic end just in front of the visceral afferent glossopharyngeal root and its caudal end just caudal to that same root. There is no break in continuity between the efferent nuclei of the facial and the glossopharyngeal nerves. Tello ('09) found essentially the same relations in Salmo trutta.

The disposition of the efferent facial nucleus to the cephalic end of the caudal visceral efferent column is most natural in such a form as the trout where the visceral afferent facial root is not so well developed as the visceral afferent portions of the glossopharyngeal and vagus nerves. The efferent facial nucleus, under the influence of the visceral afferent centers of the glossopharyngeal and vagus nerves, has been pulled caudally.

The position of the efferent facial nucleus in teleosts is subject to some variation. In general there are two main types. The trout belongs to the group with only one efferent facial nucleus. In this group also are Amia (Droogleever Fortuyn, '12) and Orthagoriscus (Burr, '28). The other type has usually two efferent facial nuclei as described by Berkelbach van der Sprenkel ('15) for Siluris glanis and Mormyrus and by Ariëns Kappers ('10) for Tinca tinca.

B. The root fibers in the trout

1. The visceral afferent roots of the facial, glossopharyngeal and vagus nerves (fig. 6). The visceral afferent facial root enters the medulla oblongata in the cephalic portion of the acustico-facial root complex. It runs caudomedially to the cephalic end of the facial lobe. The fibers enter the dorsolateral aspect of the lobe and turn sharply caudalward, only a few fibers ending at the level of entrance. The root continues caudally as a unit, not breaking up until in the region midway between the facial and glossopharyngeal nerves. 
The entering visceral afferent glossopharyngeal root runs dorsomedially to the lateral aspect of the glossopharyngeal lobe. At this point most of the fibers turn dorsally to swing around the lobe, some of them passing over the dorsal aspect of the lobe and turning ventrally down around its medial aspect before entering it. There is also a bundle which enters the lobe directly and then crosses over to the periventricular gray region. All of these fibers are lost in the general fascicular pattern, most of them turning caudalward.

The most cephalic visceral afferent vagus rootlet (fig. 6 ) is quite caudal to the visceral afferent glossopharyngeal root. The second vagus rootlet is closer to the first and the following are nearer together so that in a progressive manner, cephalocaudally, the roots approximate each other more and more closely and the vagal lobe becomes larger. The first vagus rootlet enters the medulla oblongata a short distance caudal to its level of entrance into the vagal lobe. Its size is about the same as that of the visceral afferent glossopharyngeal root. It takes a dorsomedial course to the lateral aspect of the vagal lobe wherein it enters directly instead of swinging around its borders as does the glossopharyngeal root. It passes at once into the substance of the lobe and spreads fan-wise (in transverse material) to scatter throughout the dorsomedial corner of the lobe. A few fibers also swing across into the ventral portion of the region. The courses of the second to the seventh vagus rootlets into the vagal lobe are much the same as that of the first. At caudal levels the lobe is the most dorsal structure of the medulla oblongata.

2. The efferent facial root. The neuraxes of the efferent cells of the facial nerve turn dorsally and medially to run to the lateral aspect of the medial longitudinal fasciculus, where they turn cephalically. As they proceed they shift in position so as to lie on the dorsal aspect of this fasciculus. Here they remain until the level of their emergence, where they turn laterally and course along the floor of the ventricle over the caudal cells of the efferent trigeminal nucleus. Lateral to 
this nucleus the fibers leave the floor of the ventricle and run laterally and slightly ventrally to emerge from the medulla oblongata as the most ventral and cephalic portion of the acustico-facial root complex.

\section{The fiber connections in the trout}

1. The secondary connections of the gray associated with the visceral afferent roots of the facial, glossopharyngeal and vagus nerves (fig. 6 ). At levels cephalic to the visceral afferent facial root the periventricular gray associated with the visceral

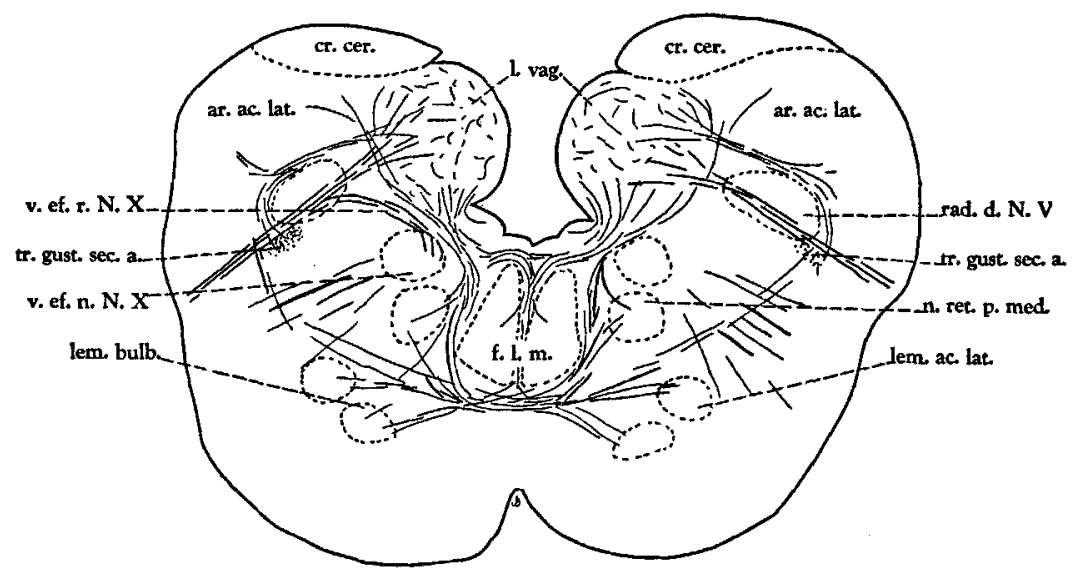

Fig. 6 A section through the eephalic portion of the vagal lobe showing its connections. The first visceral afferent rootlet of $X$ (unlabeled) is shown entering the vagal lobe. Salmo gairdneri iridens. Chrome silver. $\times 28$.

afferent region is very general in its connections. Some fibers run out laterally through the acustico-lateral area to the region of the secondary ascending gustatory tract. A few fibers join with the cerebello-motorius bundle to run down toward the midline. These connections are sparse and suggest the primitive condition found in petromyzonts. No root fibers of the facial nerve ascend into this region.

At the level of entrance of the facial nerve and caudally to almost the glossopharyngeal nerve the condition remains essentially the same as that described above. Only a few 
root fibers end in this cephalic portion of the visceral afferent area. The secondary connections are a bit more numerous but still of a primitive character. Small fascicles run laterally into the acustico-lateral area. A somewhat larger number course more ventrolaterally into the region of the secondary ascending gustatory tract. There are also additions to the arcuates from the acustico-lateral area and the cerebellum which run to the midline. The visceral fibers are lost among the arcuates. The arcuates reach the midline, cross, run a short distance laterally, and then dip sharply ventrally into the medial part of the medial reticular nucleus of the opposite side where many fibers end. Some few swing out of the lateral aspect of the reticular nucleus and over to the bulbar lemniscus system wherein they turn cephalically. The condition here described resembles strongly that found in Amia and petromyzonts. Of all these contributions, that to the secondary ascending gustatory tract is the largest. These fibers come from the thickened periventricular gray of the area just ventral and medial to the longitudinal bundles of the facial lobe and leave the lobe just ventral to the longitudinally running root fibers. Somewhat cephalic to the visceral afferent glossopharyngeal root the bundle of root fibers within the facial lobe becomes a little larger and less compact. The additional fibers are ascending fibers of the visceral afferent glossopharyngeal root. In this region the contribution to the secondary ascending gustatory tract becomes larger. There appears a small band of fibers from the most ventromedial corner of the vagal lobe which runs on the inner aspect of the arcuates from the acustico-lateral area and the cerebellum. These fibers run toward the midline along the floor of the fourth ventricle. Not all of them reach the region of the midline, some dipping down to the efferent nucleus of the same side. Other fibers run to the region of the midline and enter the dorsal part of the medial longitudinal fasciculus. This connection is prominent more caudally and will be described for that region. Traveling with the large bundle of arcuates are secondary fibers of the lobe which connect with the reticular nuclei of 
the same and opposite sides and with the adjacent bulbar lemniscus system.

Caudal to the visceral afferent glossopharyngeal root the vagal lobe (fig. 6 ) forms a large projection into the ventricle. The bundle to the secondary ascending gustatory tract is quite large at this level. Some of the fibers which pass out toward this tract turn dorsally to enter the acustico-lateral area. The direction of their conduction is not known. Most of the fibers run out toward the secondary gustatory tract, turn ventrally and join that tract. A few others seem to end diffusely among the cells of the reticular nucleus of the ventrolateral field.

Ventral and medial to the fibers passing to the region of the secondary ascending gustatory tract (fig. 6), and separated from that bundle by the descending trigeminal root, is another diffuse system of fibers leaving the lobe. These enter the ventral field just lateral to the visceral efferent column and many of them undoubtedly enter that nucleus. Others seem to sweep ventrally to join the medial part of the reticular gray. Still others cross in the ventral portion of the midline and join the bulbar lemniscus system and probably also the bulbo-cerebellar tract. Leaving the vagal lobe in the same region as this last complex are medially running fibers which join the arcuates from the acustico-lateral area. Both groups of fibers cross the midline and pass to the reticular nucleus. Some stop there while others turn out of the nucleus to go to the bulbar lemniscus system, and still others pass to the visceral efferent glossopharyngeal nucleus. The greater number of these fibers are from the acustico-lateral area, but there is a definite addition from the glossopharyngeal lobe. The arcuates from the acustico-lateral area do not enter the bulbar lemniscus system but ascend in the tract just dorsal to that system. This more dorsal group of fibers is traced to the torus semicircularis and identified as the acustico-lateral lemniscus.

Also there are found small black fibers which run medially from the lobe along the floor of the ventricle. These are seen 
more cephalically but are less clear there than in the plane under discussion. Some of these fibers end in the periventricular gray along the floor of the ventricle. Others run more medially to turn into the medial longitudinal fasciculus. They turn cephalically or caudally in this fasciculus while still others swing over to the top of the medial longitudinal fasciculus and dip down along the midline to reach the nucleus of the raphé. A few of these latter cross as they dip ventrally. Also, as more cephalically, there are connections on the dorsolateral aspect of the lobe with the acustico-lateral area.

The cephalic region of the vagal lobe is similar to that described previously. More caudally in the vagal lobe the bundle which passes to the secondary ascending gustatory tract and the acustico-lateral area becomes smaller and more diffuse and is connected almost entirely with the medial funicular nucleus. The connection that increases at this caudal level is ventral to the visceral afferent and efferent vagus rootlets. It is a broad tangle of fibers that run ventrolaterally from the lobe into the region bounded dorsally by the descending trigeminal root and ventrally by the efferent vagus nucleus and its dendrites. Many of these fibers pass almost to the periphery before turning either dorsally or ventrally. The dorsally turning fibers connect with the funicular nuclei while the others sweep to the reticular gray and the midline. Those that cross the midline run out to the bulbar lemniscus. The connections of the lobe with the efferent vagus nucleus are larger here, corresponding to the increased size of this efferent nucleus. There is a large crossing of vagal lobe fibers at the midline dorsal to and in between the medial longitudinal fasciculi. The fibers then connect with the nucleus of the raphé. From this region fibers pass laterally to the reticular nucleus and beyond that to the bulbar lemniscus. They are the same as those fibers which, more cephalically, swept to the midline ventral to the medial longitudinal fasciculus. There seem to be no connections into this latter fasciculus at this caudal level. 
Just ventral to the caudal vagus rootlets and the descending trigeminal root, and lateral to the efferent vagus nucleus, is the darkly staining field of the secondary descending gustatory tract. There is a heavy direct connection between this field and the vagal lobe. This latter connection is very large just cephalic to the calamus scriptorius, there being streams of fibers running between the areas. Caudal to the calamus scriptorius the tract moves laterally and is lost in the field ventral to the descending trigeminal root. Just cephalic to the calamus scriptorius the tract sends many fibers to the region of Herrick's ('06) funicular nucleus.

Cephalic to the calamus scriptorius the secondary descending gustatory tract becomes continuous with the somewhat more compact secondary ascending gustatory tract. This latter tract has fewer connections with the vagal lobe. It remains ventrolateral to the descending trigeminal root (fig. 6) throughout much of the medulla oblongata. Cephalic to where the afferent trigeminal root enters the medulla oblongata, the secondary ascending gustatory tract crowds up against the efferent trigeminal root along with the bulbocerebellar tract and other systems. As the most cephalic fibers of the efferent trigeminal root disappear, the secondary ascending gustatory tract moves dorsally and cephalically and enters its nucleus. It is not well differentiated from the bulbocerebellar tract in this region and can be identified best by following its turning into the secondary gustatory nucleus where its fibers run longitudinally before ending. The tract arises chiefly in the caudal portion of the vagal lobe, although some fibers join it in the more cephalic regions of the glossopharyngeal and facial lobes. Cephalic to the glossopharyngeal nerve the tract receives only small contributions. The secondary ascending and descending gustatory tracts have been described for many teleosts, being very prominent in the highly gustatory teleosts but demonstrable even in the moderately gustatory forms such as the trout and Orthagoriscus (Burr, '28). 
2. The inferior commissure of Haller (fig. 14c). As the two vagal lobes meet at the calamus scriptorius, the fibers which will form the inferior commissure immediately begin their decussation. Some of the most cephalically decussating fibers undoubtedly swing forward in the lobe of the opposite side to run up to the efferent nucleus of that side. At the level where the most cephalic fibers cross, the cells of the vagal lobe are replaced by those of the nucleus of the inferior commissure, this latter nucleus having the same fiber relations with the funicular nuclei as those described for the vagal lobe. Dorsal to the visceral commissure is a small group of differentially stained, crossing fibers which interrelate these secondary funicular nuclei. This is part of the somatic commissure. It does not become large until the more caudal region of the commissure where the visceral fibers are no longer crossing. The somatic commissure is almost entirely caudal and ventral to the visceral commissure except for a few fibers in the dorsal region of the visceral commissure.

A short distance caudal to the first appearance of the visceral commissure the cervical bundles form (fig. 14 c). There is a dorsal and a ventral bundle which are but poorly separated from each other. The latter is made up of crossed and uncrossed fibers which run caudally only a short distance, fading out when the efferent vagus nucleus, with which it is intimately associated, disappears. The dorsal bundle is larger and is also composed of crossed and uncrossed fibers. Caudal to the efferent vagus nucleus the bundles are elongated, slender fascicles just to each side of the midline about halfway between the central canal and the dorsal surface of the spinal cord. Most of the crossing fibers are somatic, but some of them are possibly from the dorsal cervical bundles. In the cephalic end of the typical spinal cord region these bundles have become very small, their fibers moving ventrally down the raphe to end in the dorsal horn region. Some fibers may leave the dorsal cervical bundles in a dorsal direction to run out with the fascicles of the somatic commissure. These latter do not cross but run dorsally to the funicular gray of the same side. 
In general, the results reported here are in accordance with those of Herrick ('08). The trout has moderately developed visceral and somatic afferent centers so that there is a balance between them in the commissural region. Neither stands out clearly from the other, the center of gravity of importance being divided between them.

3. The fiber connections of the secondary gustatory nucleus. The caudal end of the secondary gustatory nucleus (fig. 7) extends somewhat behind the point of entrance of the secondary gustatory tract. In this caudal region the connection seems to be chiefly with the lateral part of the medial reticular nucleus. This connection makes possible the discharge of impulses aroused by gustatory stimuli to the efferent trigeminal nucleus. It consists of diffusely arranged and finely medullated fibers leaving the ventral and ventromedial aspect of the secondary gustatory nucleus, to end in the lateral part of the medial reticular nucleus.

In the dorsal portion of the secondary gustatory nucleus there are fine, black fibers which run between the secondary gustatory nucleus and the granular layer of the cerebellum. The connection is sparse and diffuse. The direction of conduction is not known. Also, in this caudal portion of the secondary gustatory nucleus, there are fibers which run medially along the floor of the ventricle. Some of these turn longitudinally in the area just dorsal to the medial longitudinal fasciculus, while others cross over to the opposite side after passing dorsal to this fasciculus. This connection is much larger more cephalically.

In the middle portion of the secondary gustatory nucleus internuclear fibers are given off. These fibers seem to come mostly from cells in the lateral portion of the field. The cell bodies are intercalated between the fibers of passage just lateral to the nucleus. The fibers of passage are cerebellohypothalamic, anterior cerebello-mesencephalic and cerebellotegmental tracts. These fine internuclear fibers pass out dorsolaterally between these bundles. They then turn dorsally and medially to cross in the ventral cerebellar commissure. 
Added to these more cephalically are fibers leaving the ventrolateral aspect of the secondary gustatory nucleus and swinging in an arc to a position lateral and dorsal to the nucleus. These fibers take a dorsomedial course and cross in the valvula of the cerebellum, constituting a dorsal cerebellar commissure which is cephalic and dorsal to the larger ventral cerebellar commissure. The dorsal commissure gives off fibers to the substance of the valvula. This provides a gustato-cerebellar path. Fibers may be either homo- or contralateral, the size of the commissure indicating that many are contralateral.



Fig. 7 A transverse section through the caudal (right) and mid-regions (left) of the secondary gustatory nucleus. Salmo fontinalis. Toluidin blue. $\times 22$.

Careful examination of the commissural region failed to reveal Brickner's ('30) gustato-tectal tract. The gustatohypothalamic tract of Herrick ('05) can be traced only a short distance to the region midway between the secondary gustatory nucleus and the hypothalamus. The fibers leave the nucleus to run cephalically and ventrally for a short distance, and then are lost.

Ventrally and medially the connections to the midline increase nearer the cephalic end of the nucleus. These fibers run mediocephalically, their probable destination being largely the medial longitudinal fasciculus through which they reach 
the eye-muscle nuclei. Some of these fibers reach the medial longitudinal fasciculus and enter it, while others cross the midline to the medial longitudinal fasciculus of the opposite side. Part of them dip ventrally into the medial reticular nucleus of the same or the opposite side.

The connections of the secondary gustatory nucleus are more prominent in the trout than in Amia but much less prominent than those described by Herrick ('05, '06) for the carp and for Ameiurus.

4. The tracts entering the efferent facial nucleus. The nucleus is placed at some distance from the fourth ventricle and is therefore relatively isolated from the bulbar and acustico-lateral lemnisci that swing down to the midline. From the acustico-lateral area and facial and glossopharyngeal lobes fibers reach the efferent nucleus as small separate bundles that detach themselves from the larger arcuate bundle in the region just lateral to sulcus limitans and turn ventrally and somewhat laterally to reach the nucleus. On the medial aspect of the efferent facial nucleus there are incoming fibers from the medial part of the medial reticular nucleus. Likewise there are connections from the midline that pass ventral to this reticular nucleus. Many of these fibers represent crossed connections from the other side of the medulla oblongata, while some (part of those from the reticular nucleus) represent connections with lower centers of the brain. The dendrites of the efferent cells are fewer and smaller than in Amia. They course ventrolaterally to the ventral field, where they receive impulses from the large descending tracts from the higher brain centers.

\section{The root fibers in the carp}

1. The visceral afferent roots of the facial, glossopharyngeal and vagus nerves (figs. $8,9,10$ ). The visceral afferent facial root enters the medulla oblongata as the largest and most cephalic component of the facial, acustic and glossopharyngeal root complex. The huge bundle runs medially and somewhat dorsally with a strong caudal inclination to a position just 
lateral and dorsal to the ventricle, which is very small at this level. It runs caudally in this position to the level of the glossopharyngeal lobe, where part of it spreads out dorsolaterally and the rest moves ventrolaterally. The result of this shift is that caudally in the facial lobe there are a large bundle of fibers on the dorsolateral aspect of the lobe and a number of small fascicles in the ventrolateral portion of the lobe. These ventrolateral fibers end before the dorsolateral fibers do, so that the most caudal portion (fig. 9) of the facial lobe is supplied by the dorsolateral group of root fibers. The fibers end diffusely throughout the lobe, there being no systematic organization of cells or fibers (Herrick, '05) within the lobe.

The visceral afferent glossopharyngeal root (fig. 8) enters the medulla oblongata as the most caudal portion of the facial, acustic and glossopharyngeal root complex. The results obtained in the study of this root correspond more closely to those obtained by Mayser (1882) and Ariëns Kappers ('14) than with those described by Herrick ('05). The large root courses dorsocaudally until it rides on the medial surface of the glossopharyngeal lobe, much as does the superficial vagus root on the lateral surface of the vagal lobe. The most ventral root fibers course caudally along the lateral aspect of the visceral afferent facial fibers. The former eventually turn up into the caudal end of the glossopharyngeal lobe. The endings in the lobe are mostly confined to the medial one-half of the lobe, the lateral half being concerned chiefly with efferent fibers of the lobe.

The visceral afferent vagus roots (figs. 8, 9, 10) are so numerous and so densely packed that they cannot be separated from one another. As was described by Mayser (1882) and Herrick ('05), there is a division into two portions, a large superficial root and a smaller deep root. The superficial root (figs. 8,9 ) runs dorsally along the entire lateral aspect of the vagal lobe. The fiber bundles are large and tangled in their course, giving the root a very felted appearance. The fibers are small and not very heavily medullated. They turn 



Fig. 8 A transverse section through the level of attachment of the facial lobe to the medulla oblongata. Most of the connections of the lobe are shown. Cyprinoides carpio. Chrome silver. $\times 10$.

Fig.9 A transverse section through the vagal lobe in the plane where it reaches its greatest size, showing its connections and its root fibers. Cyprinoides earpio. Chrome silver. $\times 10$. 
into the thick cellular layer (composed of the seven bands of cells described by Herrick, '05) as small fascicles. They extend through about one-half of its thickness although individual fibers go farther. Also many fascicles break up immediately upon entry. The deep root (fig. 9) breaks up into small fascicles and runs up the inside of the cellular layer of the lobe. It gives off individual fibers and small bundles of fibers to the cellular layer. These small bundles may pierce the cellular layer to any extent, a few going as far out as the inner aspect of the superficial root, thus establishing a connection with the chief secondary neurons which lie most superficially in the cellular layer according to Herrick's ('05) description. The most cephalic deep visceral afferent root of the vagus is quite large. It runs forward and, near the cephalic end of the vagal lobe, it turns in its entirety out into the superficial root layer before spreading out into the cellular layer.

2. The efferent facial root. The fibers turn medially from the posterior efferent facial nucleus and then cephalically, forming a bundle on the dorsal aspect of the medial longitudinal fasciculus along with IX (v.ef.r.N.IX, fig. 8) until their emergence. The rest of the fibers have their origin in the anterior efferent facial nucleus. This latter nucleus is on the medial aspect of the secondary ascending gustatory tract at the level of entrance of the visceral afferent glossopharyngeal root. Its fibers run dorsally and slightly medially to reach the dorsal surface of the medial longitudinal fasciculus where they join the other efferent facial root fibers. The combined bundles then course cephalically to their level of emergence. Here the fibers turn laterally to pass dorsal to the secondary gustatory tract and the descending trigeminal root. They turn ventrally on the lateral aspect of the descending trigeminal root and leave the medulla oblongata as the most cephalic and ventral portions of the facial, acustic and glossopharyngeal root complex. This description is similar to Mayser's (1882) and Ariëns Kappers' ('10). Herrick's ('05) findings were quite different, agreeing perhaps with his much modified glossopharyngeal lobe. 
E. The fiber connections in the carp

1. The secondary connections of the gray associated with the visceral afferent roots of the facial, glossopharyngeal and vagus nerves (figs. 8, 9). a) The prefacial visceral afferent gray. The most cephalic portion of the visceral afferent centers is at the level of entrance of the visceral afferent facial root into the medulla oblongata. When the huge facial root has reached its position at the midline, and is coursing caudalward toward the facial lobe, fine, unmedullated root fibers are given off from its medial aspect. Many of these fibers end in the periventricular gray of the midline above the ventricle, while the rest course ventrally along with cerebello-motorius fibers down to the midline. These latter are joined by a few fibers from the periventricular gray of the midline. The small bundle continues its course in relation to the fascicles of the medial longitudinal fasciculus. As the cephalic limit of the facial lobe is approached these connections become somewhat more numerous. They finally give way to the connections of the facial lobe.

b) The facial lobe (figs. 8,9). The structure of the facial lobe is much as Herrick ('05) described it. The most cephalic bundle leaving the facial lobe is the secondary ascending gustatory tract of that lobe. The fibers sweep out of the lobe and go directly to the dorsal portion of the combined secondary ascending gustatory tracts of the facial glossopharyngeal and vagal lobes. If any cross the midline-and there is some evidence that a few do-they cross in the facial lobe.

Running with the same fibers is a smaller bundle which courses ventrolaterally through the dorsolateral corner of the secondary ascending gustatory tract of the facial. This smaller bundle then swings ventrally, between the descending trigeminal root and the secondary ascending gustatory tract of the vagus, and, in the ventral portion of this interspace, forms the secondary descending gustatory tract of the facial (fig. 8). 
Along with the same general group from the facial lobe there are fibers which, instead of entering the secondary ascending tract of the facial, run ventrally along the medial aspect of the latter tract to enter the lateral part of the reticular nucleus. These fibers run cephalically to connect with the anterior efferent facial nucleus. More caudally in the medulla oblongata these latter fibers run ventrally and then caudally to the efferent vagus and glossopharyngeal nuclei and to the posterior efferent facial nucleus. There are, throughout the entire extent of this connection, fibers that end on the cells of the lateral part of the reticular nucleus.

A small group of fibers from the cephalic end of the facial lobe runs to a position between the facial lobe and the ependyme of the fourth ventricle. These fibers partially cross in the periventricular gray just dorsal to the fourth ventricle. They join the small bundle of cerebello- and acustico-lateral-motorius fibers (fig. 8) which are running to the more caudal efferent nuclei. The fibers from the facial lobe lose their identity among these fibers, the combined bundles running ventrolaterally to the lateral part of the reticular nucleus.

The acustico-lateral lemniscus (fig. 8) swings dorsally and medially to arch over the secondary ascending gustatory tracts and then ventromedially to the medial longitudinal fasciculus where it turns sharply medial in between the bundles of the medial longitudinal fasciculus to reach the midline. The fibers cross the midline in bundles so that in transverse material they are present only at intervals. They split the medial longitudinal fasciculus into a dorsal and a ventral portion. After crossing, the fibers run laterally to form the main bundles of the acustico-lateral lemniscus which are just ventral to the lateral part of the reticular nucleus. A few fibers from the facial lobe are lost among these acustico-lateral fibers. Since fibers are found turning ventrally at the midline where the acustico-lateral lemniscus bundle is decussating, it is probable that the facial lobe fibers do not run out to the acustico-lateral lemniscus but turn ventrally to enter the reticular nuclei or to join the bulbar lemniscus. Some of these 
ventrally turning fibers enter the medial longitudinal fasciculus.

The largest connection (fig. 8) of the facial lobe with the bulbar lemniscus goes ventrally from the lobe along the lateral aspect of the medial longitudinal fasciculus to cross the midline below this fasciculus. At each side of the midline there are contributions to the medial portions of the reticular nuclei. The remaining fibers pass out to enter the bulbar lemniscus which is just ventral to the acustico-lateral lemniscus. Here they turn cephalically and run to the tectum. On the whole, the carp has more differentiated bulbar and acustico-lateral lemnisci than does the trout.

The posterior efferent facial nucleus and the efferent glossopharyngeal nucleus are connected with the facial lobe by fibers that run directly to them from the ventral aspect of the lobe. In the more caudal region of the facial lobe a great many tangled and unorganized connections exist between the facial and the glossopharyngeal, and between the facial and the vagal lobes. Conduction is probably in both directions. No root fibers could be found leaving the facial lobe as Ariëns Kappers ('14) had asserted was the case.

Herrick ('06) and Ariëns Kappers ('14) spoke of a prominent connection between the facial lobe and the descending trigeminal root in Ameiurus. The available carp material shows only a very slight connection which is much smaller than that found by these workers in their Ameiurus material. In the carp there is a large fascicle that passes from the facial lobe to the space between the descending trigeminal root and the secondary ascending gustatory tract of the vagus. This is the secondary descending gustatory tract of the facial. It is the only connection of an appreciable size to the region near the descending trigeminal root. It is from this bundle that a few small fibers are given off to enter the descending trigeminal root. Herrick's ('05) intermediate nucleus of the facial lobe cannot be identified in the available silver material.

The secondary descending gustatory tract of the facial runs caudally between the secondary ascending gustatory tract of 
the vagus and the descending trigeminal root (fig. 8). This relationship is kept until planes through the caudal levels of the vagal lobe (fig. 9) are reached, where the secondary ascending gustatory tract of the vagus is formed. Caudal to this level the secondary descending gustatory tract of the facial retains its medial relationship to the descending trigeminal root and, at the same time, arches dorsally and somewhat laterally so that it surrounds the latter root on two aspects (fig. 9). In the region of the vagus rootlets there are connections between the vagal lobe and the secondary descending gustatory tract of the facial. Caudal to this vagal lobe connection, the tract retains its relationship to the dorsal and medial aspects of the descending trigeminal root, until the latter begins to move dorsally in the spinal cord region. Here the secondary descending gustatory tract becomes situated on its ventral aspect. Both of the secondary descending gustatory tracts send fibers into the medial and lateral funicular nuclei (fig. 10) as Herrick ('05, '06) has reported. The combined tracts continue in a depleted state into the cervical region of the spinal cord and can be found in relationship with the dorsal horn gray as far as the material extends.

The secondary ascending gustatory tract of the facial (fig. 8) reaches its maximum size at the cephalic end of the facial lobe. Here it lies on the dorsal aspect of the secondary ascending gustatory tract of the vagus and is clearly differentiated therefrom by its less compact nature. More cephalically it becomes as compact as the more ventral fibers of the secondary ascending gustatory tract of the vagus. Throughout the course of the secondary ascending gustatory tract of the facial, and particularly in the region of the anterior efferent facial nucleus, it gives off fibers to the reticular area just medial to it. The anterior efferent facial nucleus lies very close to the medial aspect of the tract and at one point at least it sends a dendrite into the tract.

At the point of entrance of the combined secondary ascending gustatory tracts into their nucleus of termination (fig. 11) the facial portion moves medially so that the majority of its 
fibers enter the secondary gustatory nucleus medial to the fibers of the secondary ascending gustatory tract of the vagus.

c) The glossopharyngeal lobe (figs. 8, 9). Mayser (1882) and Ariëns Kappers ('14) found this lobe to be a cephalic continuation of the vagal lobe. Herrick ('05) identified it as a small area buried underneath the cephalic end of the vagal lobe. In the available material the glossopharyngeal lobe is relatively large and distinct. It stands up between the medial aspect of the vagal lobe and the lateral aspect of the facial lobe as a finger-like projection. The cephalic end (fig. 8) of the glossopharyngeal lobe joins intimately with the cephalomedial aspect of the vagal lobe and its caudal end (fig. 9) merges intimately with the lateral aspect of the facial lobe. At the level where the glossopharyngeal lobe is continuous with the vagal lobe the two lobes form an oval structure. The dorsomedial aspect of this oval is under the influence of the glossopharyngeal fibers and the rest is vagal lobe. They fuse so completely that no boundary can be definitely drawn between them. The similarity in their internal morphology can be seen here for both lobes have a laminated structure - an outer, afferent zone and an inner, efferent zone. At this same level the differences between the lobes are also evident. The vagal lobe's laminae are more definite and distinct than those of the glossopharyngeal lobe. In the latter lobe the medial, afferent zone passes gradually into the lateral, efferent zone. In contrast to the facial lobe, the glossopharyngeal lobe is more organized. The former has cells in clusters and the latter has cells in more or less definite layers. The glossopharyngeal lobe, like the vagal lobe, has polarity while the facial lobe has none.

At the cephalic end of the glossopharyngeal lobe, where it is fused with the vagal lobe, the efferent fibers of the glossopharyngeal lobe enter directly into the lobar portion of the secondary ascending gustatory tract of the vagal lobe. They are lost within this bundle. More caudally the glossopharyngeal lobe sends a separate tract from its efferent zone which ends in the longitudinal portion of the secondary ascending gustatory tract of the vagus. Fibers run ventromedially 
from the lateral aspect of the lobe down to the region just caudal to the attachment of the facial lobe to the medulla oblongata proper. These fibers, some of them heavily medullated, run dorsal to or through the dorsal portion of the secondary ascending gustatory tract of the vagus, some of the fibers ending therein. Others swing down to the lateral part of the reticular nucleus. The more dorsal fibers, for the most part, swing over toward the midline as either bulbar lemniscus fibers or as fibers to the medial portion of the reticular nucleus. The bulbar lemniscus fibers reach the midline either ventral to the medial longitudinal fasciculus or run with the acustico-lateral lemniscus fibers, in which latter case they can be traced separately as finer medullated fibers that turn ventrally at the midline to cross with their fellows ventral to the medial longitudinal fasciculus. Here it is definitely seen that they do not go to the acustico-lateral lemniscus, since they can be traced to either the medial part of the reticular nucleus or to the bulbar lemniscus.

Other fibers from the efferent portion of the glossopharyngeal lobe go dorsally to the secondary ascending gustatory tract and continue directly medially to terminate in the cephalic end of the posterior visceral efferent column, chiefly to the glossopharyngeal portion of that area. Still other efferent fibers of the glossopharyngeal lobe sweep medially and dorsally to end in the ventral portion of the facial lobe. Many enter into the small bundles, which more cephalically make up the secondary ascending gustatory tract of the facial. Other efferent fibers of the glossopharyngeal lobe run directly ventrally into the efferent area of the vagal lobe. These latter fibers are of the smaller, unmedullated variety. The caudal portion of the glossopharyngeal lobe appears as an appendage of the facial lobe. At this caudal level there are many short fibers communicating between the two lobes. Conduction is probably in both directions.

d) The vagal lobe (figs. 8, 9). Mayser (1882) and Herrick ('05) have given a detailed description of the nuclear and general fiber pattern of the vagal lobe for the carp. The 
material here studied is in close agreement with the descriptions of these workers.

The cephalic third of the vagal lobe is in intimate contact with the facial lobe in the region where the latter is attached to the medulla oblongata (fig. 8). There are many small and tangled fibers which probably conduct in both directions. Similarly, where the vagal lobe and the glossopharyngeal lobe are fused there are many short correlation fibers which probably connect the two areas (fig. 8).

The largest secondary connection of the vagal lobe is the large secondary ascending gustatory tract of the vagus which runs ventromedially in a position deep to the deep afferent root (fig. 9). The tract leaves the vagal lobe to pass to a position dorsal and medial to the secondary descending gustatory tract of the facial, where most of the fibers turn cephalie ally to form the largest fiber bundle of the medulla oblongata. The tract ends in the secondary gustatory nucleus (fig. 11). Some of the fibers of the tract end in the lateral part of the reticular nucleus which is just medial to it, forming an uncrossed vago-reticular connection. These will influence the efferent vagus nucleus, since the latter sends many of its long dendrites into the reticular area, as well as influence lower centers by means of reticulo-spinal bundles.

Other fibers which leave the vagal lobe in the same bundle run farther medially to cross the midline just ventral to the medial longitudinal fasciculus. These fibers are crossed and uncrossed vago-reticulars and crossed components of the bulbar lemniscus. Their course around the medial longitudinal fasciculus bundles is variable, as was found to be the case for the glossopharyngeal and facial components of the bulbar lemniscus (figs. 8,9). A further addition in the vagal lobe region is made by fibers which cross the most ventral portion of the midline. These turn cephalically and join the spino- and bulbo-cerebellar tracts farther forward, forming a crossed vago-cerebellar connection.

The fibers of the acustico-lateral lemniscus are fewer in the vagal lobe region. Some fibers from the vagal lobe join these 
acustico-lateral fibers as the latter course to the midline. Here again, as indicated in the facial and glossopharyngeal regions, the fibers from the vagal lobe probably all turn ventrally at the midline to join the other fascicles from the vagal lobe to the bulbar lemniscus.

There is a strong direct connection from the cellular layer to the efferent nucleus of the vagal lobe. This connection is strongest on the ventromedial and dorsolateral aspects of the efferent vagus nucleus (fig. 9). Among the fibers that go to the midline are some that run dorsolaterally, after crossing, to the efferent vagus nucleus of the opposite side.

In the vagal lobe, from the narrow space between the deep visceral afferent root and the secondary gustatory tract of the vagus, there are fibers which pass medially between and at right angles to the efferent vagus rootlets. They form an addition to the secondary descending gustatory tract of the facial on the latter's dorsal and lateral surfaces. They adhere closely to the larger bundle but remain distinct from it through their darker stain. Thus these fibers form a separate secondary descending gustatory tract of the vagus (figs. 9, 10). They adhere to, follow, and have a termination similar to that of the secondary descending gustatory tract of the facial.

Herrick ('05) described the secondary descending gustatory tract of the vagus as coming from the secondary gustatory tract of the vagal lobe and turning into the substantia reticularis to run caudally. The available material (fig. 10) shows relations similar to those Herrick described. Some of the fibers may be traced to the midline of the inferior commissure, where they cross. Others continue caudally on the medial aspect of the secondary descending gustatory tract of the facial to connect with the funicular nuclei.

e) The intermediate nucleus of the vagal lobe (fig. 10). As the vagal lobe is traced caudally its afferent portion fades out while the efferent nuclear region becomes continuous with the intermediate nucleus, which in turn becomes the nucleus of the inferior commissure. The visceral afferent layer of the vagal lobe is not directly continuous with the intermediate 
nucleus. There are many fibers of the secondary ascending gustatory tract, however, which do run caudally and dorsomedially, as Herrick ('05) has described, into the intermediate nucleus. Thus the intermediate nucleus has afferents in two ways from the vagal lobe-those from the secondary descending gustatory tracts of the facial and vagus centers and those from the secondary gustatory tract inside the vagal lobe. Also there are afferent vagus root fibers which run directly from the exterior into the intermediate nucleus. Efferent fibers likewise leave the nucleus directly from efferent cells in its



Fig. 10 A transverse section through the caudalmost portion of the brain stem. The right side of the section is farther caudad than the left. Cyprinoides carpio. Chrome silver. $\times 14$.

dorsomedial region. Their dendrites run out through the intermediate nucleus. The intermediate nuclei of the two sides approach each other and many fibers run between them. Finally they merge in the commissural region as the nucleus of the inferior commissure.

2. The inferior commissure of Haller (fig. 10). The inferior commissure is divisible into two parts, a dorsocephalic or visceral commissure and a ventrocaudal or somatic commissure. The former is much the larger of the two, as is to be expected in a form with so highly developed a visceral afferent system. The material shows, as Herrick ('08) described, 
that the visceral afferent root fibers of the vagus nerve pass directly to the inferior commissure and cross. These root fibers pass through the intermediate nucleus, where some of them end before the midline is reached. In the cephalic portion of the commissure, where the two intermediate nuclei approach each other, there are large efferent cells close to the midline. These are the most caudal cells of the efferent vagus nucleus. Running in between them are fibers that represent crossed connections from the intermediate nucleus of the opposite side.

As soon as the two intermediate nuclei begin to exchange a large number of fibers, descending bundles are formed on either side. These descending fibers may be divided into two portions: the medial and the lateral cervical bundles of Ramón y Cajal. The lateral bundle disappears first by contributing to the medial and lateral funicular nuclei and to the ventral horn region. There is still a small visceral crossing at the levels of the somatic commissure. This crossing is from the medial cervical bundle out into the medial funicular nuclei of the opposite side. The medial cervical bundle runs farthest caudally, its fibers leaving the bundle and coursing ventrally with the ventrally swinging fibers of the lateral funicular nucleus to end in the efferent nucleus of the ventral horn. Some of them may run dorsally into the lateral funicular nucleus of the same side as was found in the trout. The somatic commissure is smaller than the visceral and not entirely separated from it. It contains more heavily medullated fibers which come from the medial and lateral funicular nuclei and the dorsolateral fasciculi.

3. The fiber connections of the secondary gustatory nucleus (fig. 11). The secondary gustatory nucleus is a large oval mass at the base of the cerebellum just cephalic to the acusticolateral area, ventral to the crista cerebellaris, and dorsal to the large longitudinal tracts of the ventrolateral field of the medulla oblongata. Dorsally, cephalically and caudally the nucleus is encapsulated by afferent and efferent cerebellar fibers. Medially it is bounded by its own internuclear com- 
missure. Laterally it reaches the edge of the medulla oblongata. Its chief connection is its internuclear commissure. Here a great many fibers cross, both secondary and tertiary in type. They may end in the secondary gustatory nucleus of the opposite side or run directly out into tertiary connections, the material giving no evidence one way or the other.

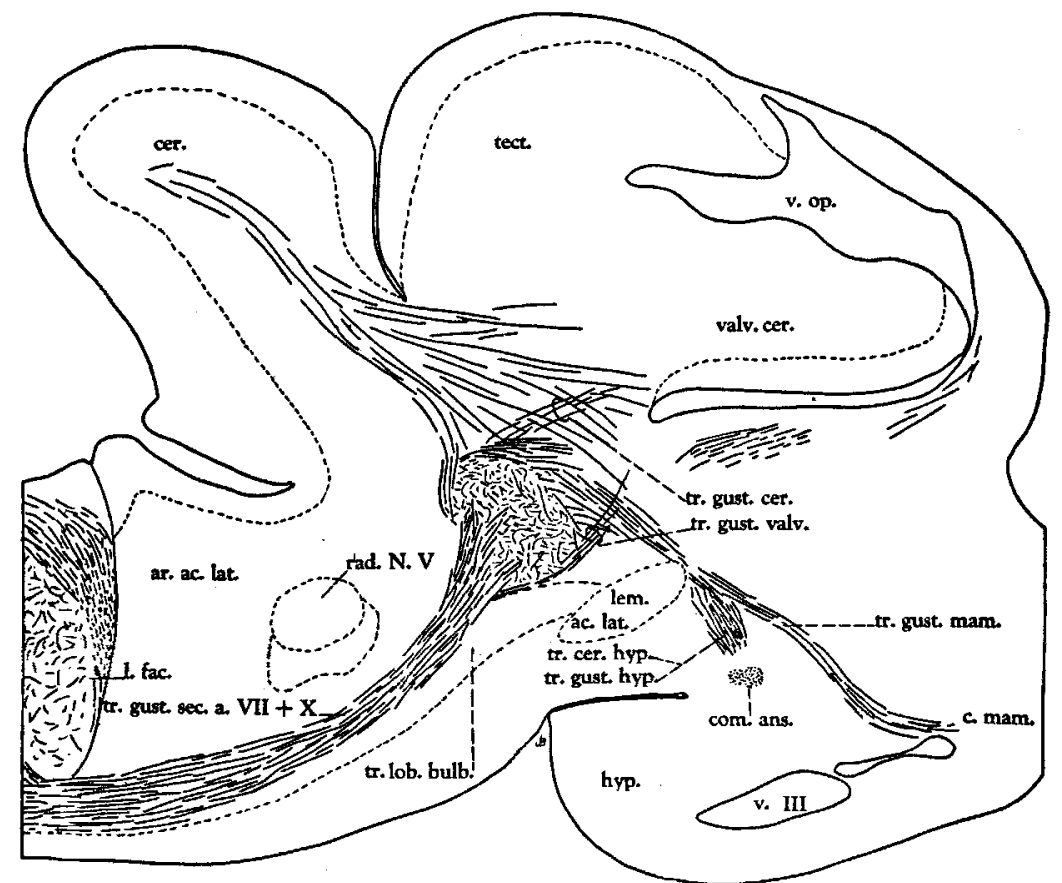

Fig. 11 A sagittal section through the secondary gustatory nucleus showing many of its connections. The course of the tractus gustato-mamillaris is indicated. Cyprinoides carpio. Chrome silver. $\times 10$.

The connection with the reticular gray associated with the efferent trigeminal nucleus is smaller than would be expected from Ariëns Kappers' ('14, '20) descriptions. Herrick ('05) described more nearly what is found in the material available. Directly caudally and caudomedially the secondary gustatory nucleus is in close relationship with the lateral part of the reticular nucleus. There are many small fibers interrelating the two areas. The reticular nucleus is in intimate contact 
with the cephalic portion of the ventral efferent trigeminal nucleus. Medial to the secondary gustatory nucleus there is reticular gray which is associated with the secondary gustatory nucleus and also the dorsal efferent trigeminal nucleus.

From the ventrolateral aspect of the secondary gustatory nucleus there are a great many small, black fibers that leave the nucleus and swing in an arc to the midline. Interrupting their passage is the medial part of the reticular nucleus. Herein many of the fibers synapse, although some pass on through it. The fibers which reach the midline turn dorsally. They cross as they run dorsally, the majority doing so between the medial longitudinal fasciculi just below the ventricle. After decussating they pass laterally to the bulbar lemniscus wherein they turn cephalically. Certain of the fibers, after crossing at the midline, continue their dorsal course and arch over the top of the medial longitudinal fasciculus and join the lateral part of the reticular nucleus of the opposite side, some stopping there and others passing on through to the bulbar lemniscus. At the midline many crossed and uncrossed fibers turn into the medial longitudinal fasciculus.

The most cephalic fibers of the gustatory commissure run ventrolaterally, following a course on the outside of the acustico-lateral lemniscus. They turn and run medially, ventral to this latter bundle, and finally pass into the bulbar lemniscus which, at the levels of the secondary gustatory nucleus, is ventromedial to the acustico-lateral lemniscus.

The tertiary gustatory tract of Herrick ('05) shows in the available material (fig. 11) very much as he described it. No crossing of these fibers could be found. In transverse sections the fibers are found to enter the hypothalamus on the dorsal aspect of the lobo-bulbar tract. The fibers dip into the hypothalamus in the region just cephalic to the ansulate commissure. If they make any contribution to this commissure it is very small and cannot be found in the material. The gustato-hypothalamic and cerebello-hypothalamic fibers are intermingled to a considerable extent and lie on the dorsal aspect of the lobo-bulbar tract. 
In sagittal section there are fibers which can be traced to the mammillary body (fig. 11). These gustato-mammillary fibers run from the cephalic end of the secondary gustatory nucleus and have a less ventrally inclined course than the gustato-hypothalamic fibers. The bundle courses cephaloventrally until in the mammillary region, where it breaks up and is lost. Herrick ('05) mentioned the possibility of this connection but did not find it.

The group of gustato-cerebellar connections is very diffuse (fig. 11). In general the fascicles fall into two main paths. The more prominent and cephalic is the connection to the valvula of the cerebellum. This pierces the substance of the valvula and is not to be confused with Herrick's fiber path to the lateral valvular nucleus. The connection into the valvula proper takes its origin from the dorsal surface of the secondary gustatory nucleus. There are several fasciculi of fibers in this connection and while they start from approximately the same place their course varies in that one runs directly cephalically into the valvula along the latter's floor while the other turns dorsally as well as cephalically to go into the substance of the valvula.

The connection with the body of the cerebellum is much more diffuse. As the fibers come down from the cerebellum they push against the entire caudodorsal surface of the secondary gustatory nucleus and, pressing tightly against that nucleus, sweep around it to reach their various destinations. From the caudodorsal surface of the secondary gustatory nucleus, there are fine black fibers that pass up into the cerebellum in company with the fibers just described and which form no fasciculi but course as individual fibers.

Herrick's connection with the lateral valvular nucleus can be found, as he described it, consisting of small bundles of fibers running cephalically and dorsally to this nucleus from the inferior surface of the secondary gustatory nucleus (fig. 11). There are, in addition to this connection, other small and diffuse connections to the 'Übergangsganglion' region just cephalic to the secondary gustatory nucleus from the cephalic face of this last-mentioned nucleus. 
The caudal end of the secondary gustatory nucleus is covered on its dorsolateral and ventrolateral aspects by the fiber bundles connecting the medulla oblongata with the cerebellum. Also some of these fibers swing forward under the secondary gustatory nucleus to connect with the lateral valvular nucleus. From the edges of the secondary gustatory nucleus there are many small, fine fibers joining this complex. The fibers from the secondary gustatory nucleus are directed laterally and ventrally, which indicates that they are either gustatomotorius, to the efferent nuclei of the medulla oblongata, or bulbo-gustatory in character. The latter interpretation seems improbable in view of the large secondary ascending gustatory tract. Therefore such fibers probably constitute a connection to the medulla oblongata from the secondary gustatory nucleus. They are intermingled at their origin with part of Herrick's connection from the secondary gustatory nucleus to the lateral valvular nucleus. No sign of a connection with the tectum, such as Brickner's ('30) gustato-tectal tract, can be found.

4. The tracts entering the efferent facial nucleus. The posterior efferent facial nucleus receives many fibers from the facial lobe as well as from the glossopharyngeal lobe. The dendrites of the cells of the posterior efferent facial nucleus course ventrolaterally to the lateral part of the reticular nucleus. In this manner, the posterior efferent facial nucleus is entirely under the influence of the three visceral afferent lobes.

The anterior efferent facial nucleus is composed of two portions, a large celled, cephalodorsal and a smaller celled, caudoventral portion. The caudal part of the nucleus lies on the lateral aspect of the reticular gray and in close relationship to the secondary ascending gustatory tracts of the vagus and facial. It is the neurobiotactic influence of this large bundle that has drawn the caudal cells of the anterior efferent facial nucleus ventrally and laterally (see also Ariëns Kappers ('10) for Tinca tinca). The cephalic end of the anterior efferent facial nucleus lies on the lateral aspect of the medial longitudinal fasciculus. Fibers from the acusticolateral area and cerebellum come into relationship with the 
cells. The dendrites, however, sweep down to the lateral part of the reticular substance where they come into relationship with the ascending gustatory tracts. Gadus, Hippoglossus and Pleuronectidae (Ariëns Kappers, '10) are teleosts with the same general pattern for the efferent facial nuclei as that given here.

\section{Amphibians (Necturus, Amblystoma, Siren and Rana)}

\section{A. The nuclear groups}

1. The nucleus of the fasciculus solitarius (figs. 12, 13, 15, 16). At the level of entrance of the facial nerve the fasciculus solitarius of tailed amphibians (figs. 12,13) is detached from the periventricular sensory field, lateral to the sulcus limitans and dorsal to the acustic root. Only a few small spindle-shaped cells are present, tightly pressed to the dorsal, medial and ventral aspects of the fasciculus. More caudally the fasciculus moves medially and the cells related to its medial aspect become extremely large and round, many of them showing large tigroid granules. The cells on the ventral aspect give way to the large celled lateral vestibular nucleus.

Just cephalic to the visceral afferent glossopharyngeal root the fasciculus solitarius moves medially so that its medial aspect is buried in the layers of the sensory field near the sulcus limitans. The cells between the fasciculus and the ependyme are from three to four deep. The dorsomedial and ventromedial boundaries of the nucleus of the fasciculus solitarius are impossible to delimit since the cells do not differentiate from the others of the sensory field. A few smaller, spindle-shaped cells are scattered around the lateral aspect of the fasciculus.

At the level of the first vagus rootlet (figs. 12,15) the cells become more numerous and more compact. The nucleus and fasciculus protrude medially into the ventricle above the sulcus limitans and reach their greatest size. The dorsal boundary is a clear space ventral to the acustico-lateral cells. The dorsomedial cells of the nucleus of the fasciculus solitarius are somewhat smaller and more numerous than those in the 
ventromedial corner. The ventral boundary is a slight gap between the larger cells of the nucleus and the smaller cells of the reticular gray.



Fig. 12 A transverse section through the level of entrance of a vagal rootlet. Siren lacertina. Toluidin blue. $\times 22$.

Fig. 13 A transverse section caudal to the level of entrance of the vagus nerve showing the nucleus of the fasciculus solitarius. Rana catesbiana. Toluidin blue. $\times 25$. 
In the caudal vagus nerve region the fasciculus solitarius and its nucleus, although smaller, protrude farther into the ventricle. The cells, which surround the fasciculus on all sides except for a small lateral area, are almost uniform in size, those in the region of the sulcus limitans being slightly smaller. Dorsally there remains only a small clump of cells of the acustico-lateral area. Just cephalic to the calamus scriptorius the nucleus of the fasciculus solitarius fades out, giving way to the small granule cells of the inferior commissure. The above description applies to Siren lacertina (fig. 12). Amblystoma is less well differentiated.

The relations and the relative development of the nucleus of the fasciculus solitarius in the frog (figs. 13, 16) are essentially the same as in urodeles. The great differences in their appearance are due to the greater differentiation of the entire nervous system of the frog than of the urodeles and are not significant for this study. In the frog the nucleus is a discrete mass the cephalic half of which is fused with the nucleus of the descending trigeminal root, the latter for the first time being well organized. Cells on the ventrolateral aspect of the fasciculus solitarius indicate what Ariëns Kappers and Hammer ('18) called the nucleus parasolitarius.

2. The nucleus of the inferior commissure of Haller. At the calamus scriptorius of urodeles, and for some distance caudally, the small darkly staining cells remain grouped around the dorsal, medial and ventral aspects of the spinal fibers of the fasciculus solitarius. The ventral cells are adjacent to the medial funicular nucleus and the nucleus of the descending trigeminal root. At one or two levels the cells of the inferior commissure become continuous with each other across the midline (fig. $14 \mathrm{~d}$, unlabeled), forming the commissural nucleus of Ramón y Cajal. They are not so plentiful as those found by Herrick ('30) in Necturus. In the frog

Fig. 14 A series of transverse sections through various levels of the inferior commissure of Haller. a, Entosphenus appendix. Toluidin blue. $\times 28$. b, Amia calva. Toluidin blue. $\times 22$, e, Salmo salar gehago. Chrome silver. $\times 28$. d, Necturus maculatus. Chrome silver. $\times 28$. e, Rana catesbiana. Chrome silver. $\times 25$. f, Anolis carolinensis. Chrome silver. $\times 28$. g, Columba domestica. Chrome silver. $\times 18$. h, Mus domesticus. Chrome silver. $\times 18$. 

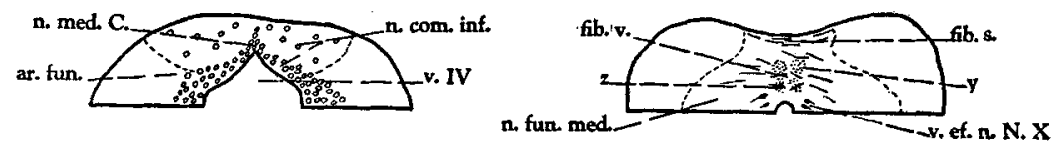

a

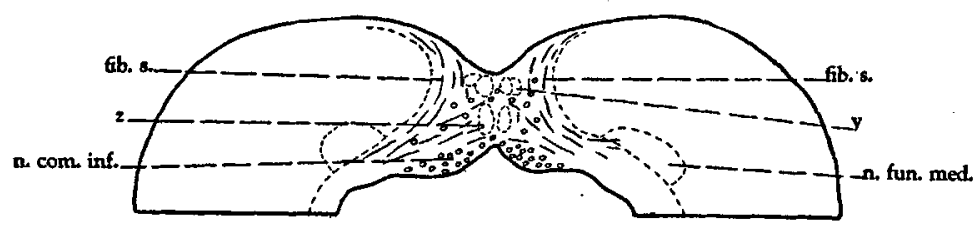

b



d

e



$\mathbf{8}$
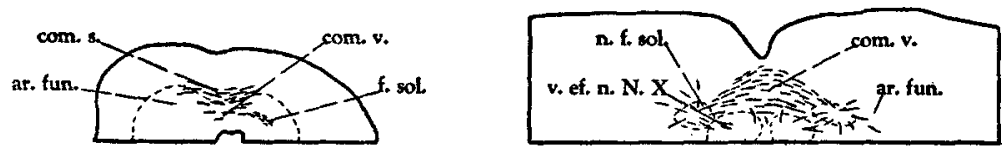

f 
(fig. $14 \mathrm{e}$ ) the nucleus of the inferior commissure is somewhat larger, the only essential difference being that the median nucleus of Ramón y Cajal is more definite than in urodeles.

3. The secondary visceral nucleus (figs. 17,18 ). In urodeles the nucleus (fig. 17) is a dorsolateral extension of the subcerebellar tegmental eminence (Herrick, '30). It is identified best by the fibers which lead to it, the secondary ascending visceral tract. The nucleus is just ventral to cerebellar gray. It is at the level at which the lateral bulbo-tectal tract is sweeping down from the tectum and at which the spinocerebellar tract is moving dorsally to the cerebellum, as Herrick ('14, '17, '30) found. This nucleus is easily identified in Necturus and in Amblystoma but not with certainty in Siren.

In the frog the secondary visceral nucleus (fig. 18) is found to be very much as Larsell ('23, '24) described it, i.e., much larger and more clearly delimited than in urodeles. It is lateral and cephalic to the nucleus of the cerebellar commissure and caudal and lateral to the nucleus isthmi. The nucleus in the frog is extremely large when considered in relation to the small size of the secondary ascending visceral tract. It is doubtful, in the available material, whether more than just the generalized and looser caudal end of Larsell's ('23) secondary visceral nucleus is concerned with visceral impulses.

4. The efferent facial nucleus. In Necturus and Amblystoma the facial portion of the posterior visceral efferent column has its cells cephalic to and mixed in with those of the efferent glossopharyngeal nucleus and the cephalic end of the efferent vagus nucleus. Siren has its efferent facial nucleus cephalic to the efferent glossopharyngeal nucleus. This pattern is similar to that found by Ariëns Kappers ('12, '20) and Black (' 17 a) in urodeles. The nucleus extends from the area just ventral to sulcus limitans to a point about halfway between the sulcus limitans and the medial longitudinal fasciculus. In between the efferent facial nucleus and this fasciculus are cells which are larger, in many places, than are the cells of the efferent nucleus. These large cells comprise Herrick's ('30) motor tegmental nucleus. The efferent facial nucleus 
is separated from the ependyme of the fourth ventricle by a layer of small, round reticular cells, three or four neurons thick.

In the frog the cells of the efferent facial nucleus are large, typical, multipolar neurons. The position of the nucleus corresponds closely to that found by Black ('17 a) in Rana catesbiana and is slightly different from that found by Röthig ('13) in Rana fusca and Bufo. That is to say, in Rana catesbiana the cephalic end of the nucleus is at the level of emergence of the efferent facial root and the caudal end of the nucleus is a short distance caudal to the level of emergence of the root. This is a marked modification from the condition in the urodeles where the efferent facial nucleus is part of the caudal visceral efferent column. The condition in Rana more closely approximates that found in petromyzonts than in any other form here studied, there being but a slight gap between the efferent facial and the efferent trigeminal nuclei in both these forms.

\section{B. The root fibers}

1. The visceral afferent roots of the facial, glossopharyngeal and vagus nerves (figs. 12, 15, 16). In urodeles the visceral afferent facial root enters just dorsal to the acustic root as Norris ('13, Siren) and Herrick ('30, Necturus) have described. The bundle runs medially and slightly dorsally to the fasciculus solitarius region, where some of the fibers bifurcate and others simply turn either forward or backward. The ascending fibers are part of the prefacial portion of the fasciculus. This prefacial portion contains fibers from the glossopharyngeal nerve and possibly even from the vagus nerve as Herrick ('30) suggested. It can be traced to the level of the afferent trigeminal root where its fibers are finally dissipated in undifferentiated gray. The descending portion of the visceral afferent facial root runs back into the glossopharyngeal and vagus nerve regions, and mixes in with roots of these latter nerves. Fibers end at all levels within the nucleus of the fasciculus solitarius. 
The visceral afferent glossopharyngeal root enters the medulla oblongata just dorsal to the acustic root. The fibers pass medially and dorsally in an are to reach the fasciculus solitarius, where more than half of them turn caudally. No
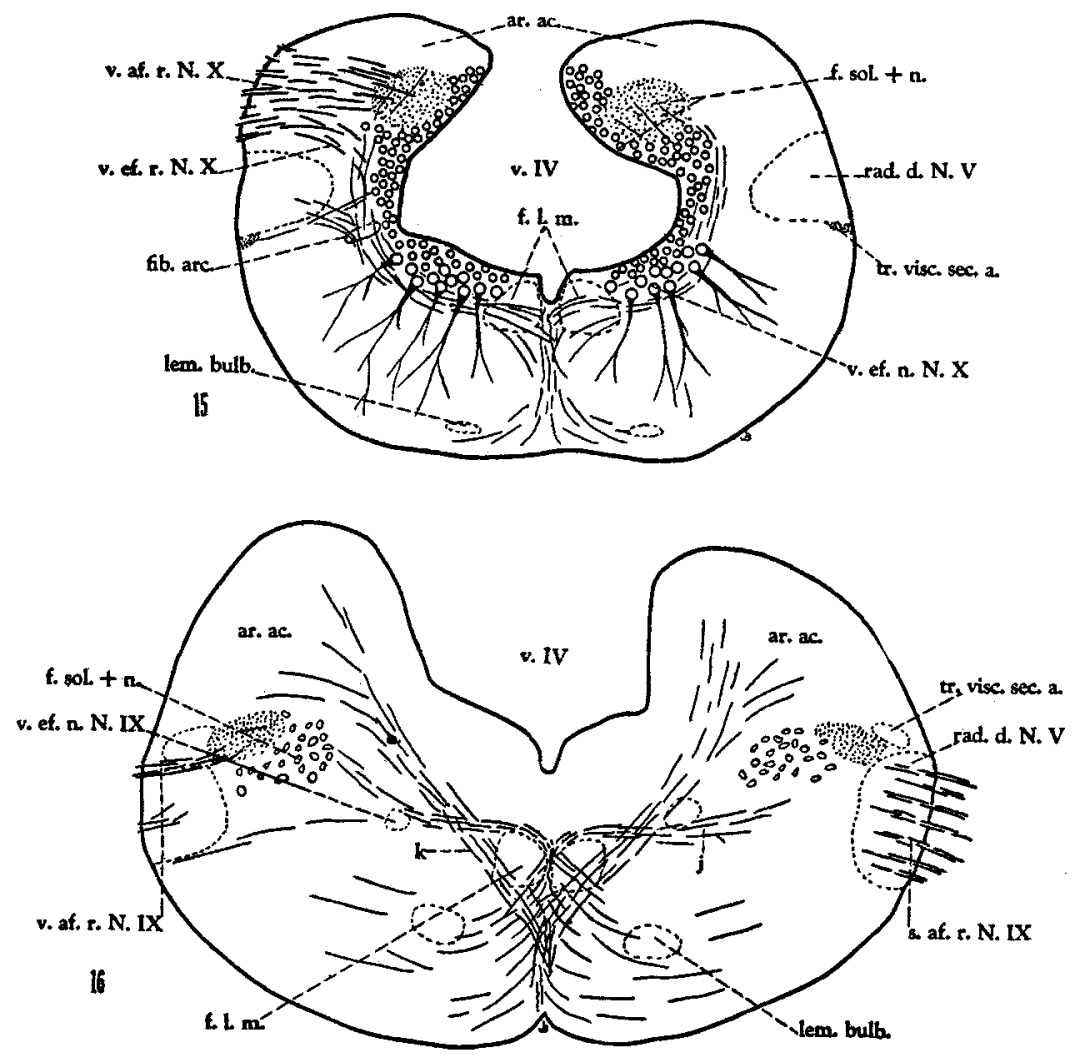

Fig. 15 A transverse section through the candal portion of the nucleus of the fasciculus solitarius showing its major connections. Necturus maculatus. Chrome silver. $\times 28$.

Fig. 16 A transverse section at the level of entrance of the glossopharyngeal nerve, showing the arcuate system of the medulla oblongata. Rana catesbiana. Weigert iron-hematoxylin. $\times 25$.

bifurcating fibers can be found. Some of the fibers course forward to contribute to the prefacial portion of the fasciculus solitarius, others caudalward into the region of the visceral afferent vagus rootlets (fig. 15). Herrick ('30) described a 
somatic afferent component of the glossopharyngeal nerve in Necturus. In the material available for study this root runs to the ventromedial aspect of the fasciculus solitarius just ventromedial to the main visceral afferent root. Thus there seem to be two visceral afferent roots in the glossopharyngeal nerve.

The visceral afferent vagus rootlets (figs. 12, 15) enter the medulla oblongata and swing dorsomedially, arching just dorsal to the descending trigeminal root. This pattern is common to the three urodeles studied. The fibers enter the fasciculus solitarius and turn either forward or caudalward, the latter fibers appearing to be more numerous. The more caudal rootlets send some of their fibers caudalward into the spinal cord. Four visceral afferent vagus rootlets are found in Siren. Amblystoma has at least two whereas Herrick ('14) found only one. Necturus has only one, agreeing with Kingsbury (1895).

Rana catesbiana (fig. 16) is similar to the urodeles studied with the exception that its visceral afferent facial root enters ventral to the acustic root. A prefacial fasciculus solitarius that has the same extent as that of urodeles is found in the frog. The facial root is relatively smaller than in urodeles, whereas the glossopharyngeal root (fig. 16) is relatively larger. Ariëns Kappers and Hammer ('18) found two visceral afferent vagus rootlets in the frog while the available material shows only one.

2. The efferent facial root. The neuraxes of the efferent facial nucleus of tailed amphibians course dorsomedially from their cells of origin to occupy a position on the dorsomedial aspect of the posterior visceral efferent column. Here they turn sharply cephalically to pass forward and slightly medially, coming to lie on the dorsolateral aspect of the medial longitudinal fasciculus. In Necturus the root divides into two parts. These have been found essentially as Herrick ('30) described them. Siren and Amblystoma are different from Necturus. Their efferent facial fibers leave the medulla oblongata in one root. 
In the frog the root is much shorter than in urodeles. The root fibers gather on the ventral aspect of the efferent facial nucleus and pass laterally and slightly cephalically to the dorsomedial aspect of the descending trigeminal root, at which point they dip sharply ventrally to pass through the ventromedial portion of the descending root to the surface of the medulla oblongata.

\section{The fiber connections}

1. The secondary connections of the nucleus of the fasciculus solitarius (fig. 15). In the caudal regions of the medulla oblongata of Necturus, a few small, black fibers are found leaving, usually, the ventral portion of the nucleus of the fasciculus solitarius and passing ventrally to the general region just ventrolateral to the descending trigeminal root, where they turn cephalically (fig. 15). The secondary ascending visceral tract retains its ventral relationship to the descending trigeminal root until the latter reaches its level of entrance. The ascending visceral tract then passes dorsally along the periphery of the medulla oblongata to end higher up, deep to the auricular area, in the more or less undifferentiated gray just dorsolateral to the region, spoken of by Herrick as the subcerebellar tegmental eminence. The tract is only moderately differentiated throughout its course and stands out best at its termination point as it arches dorsally to end in its visceral gray (fig. 17). The tract becomes quite scattered when it leaves the periphery of the medulla oblongata. It is just medial to the spino-cerebellar tract and mingled somewhat with the fibers of the lateral tecto-bulbar tract. The cephalic continuation of the secondary ascending visceral tract cannot be found.

As in urodeles, so also in Rana the secondary ascending visceral tract is small and followed only with some difficulty. The tract takes its origin chiefly from the more caudal portions of the nucleus of the fasciculus solitarius. The fibers of the tract pass laterally from the nucleus, around the ventral border of the fasciculus, and turn cephalically in the area just 
dorsal to the descending trigeminal root (fig. 16). They retain this position until cephalic to the level of entrance of the trigeminal nerve. Here they are joined by the spinocerebellar tract, and continue forward to the caudal end of the secondary visceral nucleus of Larsell ('23, '24), into which they enter (fig. 18). The tract enters only the caudal end of the nucleus (fig. 18). The larger cephalic portion seems to be occupied chiefly with fibers of passage.

In Necturus and Amblystoma the prefacial portion of the nucleus of the fasciculus solitarius is only poorly differentiated, whereas in Siren it is larger with a correspondingly greater clarity for its secondary connections. Fibers from the nucleus join the arcuates from the acustico-lateral area. These arcuates have several paths as Herrick ('30, Necturus) reported. In Siren the arcuates cephalic to the facial root seem to take the same routes. Some of the arcuates remain close to the boundary line between the white and gray substance, while others, at the sulcus limitans, swing more ventrally to pass in small fascicles through the ventral field to the midline. The arcuates that remain near the boundary line between the white and gray substance arch dorsally to the medial longitudinal fasciculus bundles and then dip ventrally at the midline to cross just ventral to them. As these more internal arcuates pass ventral to and through the efferent trigeminal nucleus fibers are given off, so that the prefacial fasciculus solitarius mediates some small influence over it. The arcuates that cross the midline cannot be followed at this cephalic level in Siren with any degree of certainty. Their destination is probably the bulbar lemniscus.

At levels caudal to the facial root the secondary connections of the nucleus of the fasciculus solitarius are more numerous, although, as more cephalically, they join the arcuate system. Some of the areuate fibers turn into the medial longitudinal fasciculus of either the same or the opposite side. The great majority of the fibers pass on through or ventral to the fasciculus, to cross the midline between and below the fasciculus bundles and to course laterally with a strong ventral tilt. 
These fibers pass out to that area which Herrick ('30) designated the general bulbar lemniscus (or bulbo-tectal and thalamic tracts) and turn cephalically (fig. 15). The material here studied indicates, particularly for Necturus and Siren, that there are more contributions to the bulbar lemniscus than Herrick ('30) would allow. This is particularly true in the most caudal levels of the medulla oblongata where the fasciculus solitarius and its nucleus are quite large and the acusticolateral area quite small. The inner arcuates also carry many fibers that end in relationship with the posterior visceral efferent column. Many of these fibers come from the nucleus of the fasciculus solitarius as Herrick ('30) also observed.

In Rana the most noticeable group of arcuates (fig. 16) is that coming from the most dorsal portion of the acusticolateral area. They sweep ventrally and slightly medially in a straight line to the median raphé, where they cross. Their straight course, with no medial turn at the sulcus limitans, carries these fibers to the ventral portion of the raphé, where they cross and pass out laterally to the acustic lemniscus.

The other, somewhat less bulky group of arcuates (fig. 16), comes, in general, from the more ventral portions of the acustic area. They pass medially at the sulcus limitans toward the midline along the outer border of the periventricular gray. The majority of the fibers arch dorsally around the medial longitudinal fasciculus and at the midline dip ventrally and cross. They then pass out laterally to the more dorsal and medial longitudinal tracts of the ventral field. This latter arcuate group also carries fibers to the efferent nuclei of the opposite side.

The nucleus of the fasciculus solitarius of the frog contributes to the arcuate system that takes its origin from the ventral portion of the acustic area. A greater number of both crosses and uncrossed fibers passes to the efferent glossopharyngeal and efferent vagus nuclei than to the efferent facial nucleus.

There also seem to be a number of scattered correlation fibers to and from the acustic area and the nucleus of the descending trigeminal root, in the frog, although this latter 
nucleus is scarcely separable from the more ventral portion of the nucleus of the fasciculus solitarius. These connections increase caudally.

2. The inferior commissure of Haller (fig. $14 \mathrm{~d}, \mathrm{e}$ ). Just cephalic to the calamus scriptorius of Necturus the fasciculus solitarius begins to become noticeably depleted, its fibers ending on the nucleus of the fasciculus solitarius, so that at the calamus only a small bundle of fibers is left, surrounded on its medial, ventral and ventrolateral aspects by the cells of the inferior commissure (fig. $14 \mathrm{~d}$ ). Shortly caudal to the calamus scriptorius the small visceral commissure begins. Some of its fibers pass directly from the caudal continuation of the fasciculus solitarius, while others have their cells of origin in the nucleus of the inferior commissure.

Some of the fibers of the visceral commissure join the poorly organized gray of the medial funicular nucleus and the nucleus of the descending trigeminal root which is scattered ventrally and ventrolaterally to the small nucleus of the inferior commissure. Crossed and uncrossed fibers of the visceral commissure join the descending cervical bundles which are continuous across the midline. The descending cervical bundles run only a short distance caudally, their fibers then passing dorsolaterally into the dorsal funiculus and its nucleus.

The somatic commissure is as small and diffuse as the visceral commissure. Its fibers decussate ventral to the visceral commissure and, on the whole, somewhat caudal, although there are several transverse sections wherein both are found.

In the frog material both Weigert and silver preparations show that the great majority of fibers of the fasciculi solitarii are unmedullated near the calamus scriptorius, as Ariëns Kappers and Hammer ('18) have described. As the fasciculi continue caudalward they exchange a number of fibers, but the majority seem to remain uncrossed. Wallenberg ('07) traced the medullated fibers to the third cervical segment.

As in urodeles, so in the frog (fig. $14 \mathrm{e}$ ), a combined descending cervical bundle is formed which passes caudalward for 
an indeterminate distance. The descending bundles give off fibers dorsally to the descending acustic root area, and ventrolaterally to the region of the nucleus of the descending trigeminal root and the funicular nuclei (fig. 14 e). More caudally this latter connection gives way to the connections with the dorsal horn region. On the whole the inferior commissure of the frog is the same as that of urodeles.

3. The fiber connections of the secondary visceral nucleus (figs. 17, 18). From the lateral aspect of this nucleus in Necturus a few fibers pass laterally and dorsally to enter the cerebellum. These fibers pass through the cerebello-spinal tract to run dorsally along its lateral aspect. Whether they enter the cerebellar commissure is difficult to say. Tertiary fibers leave the cephalic portion of the secondary visceral nucleus, passing ventrally. They form the ventral portion of what Herrick ('30) termed the hypothalamic-tegmental system, and are but poorly developed in the available material. A prominent connection is the viscero-auricular tract which passes ventral to the cerebello-spinal tract and ramifies in the most cephalic end of the auricular lobe (fig. 17).

In the frog the connections of the secondary visceral nucleus (fig. 18) are more poorly developed than in the tailed amphibians. Some evidence of a viscero-tectal connection is found. The connection with the cerebellar commissure and its nucleus is present. Larsell's ('23, '24) viscero-hypothalamic tract does not show well in the available material.

4. The tracts entering the efferent facial nucleus. In tailed amphibians the more internal of the arcuates that pass toward the midline from the acustico-lateral area, from the nucleus of the descending trigeminal root and from the fasciculus solitarius, pass ventral to and through the efferent facial nucleus. They give off stem fibers and collaterals to the nucleus as they pass by. These same arcnates decussate at the midline and send fibers laterally to the efferent facial nucleus of the opposite side. The efferent facial nucleus of the frog is situated so that the great majority of the arcuates pass close to it. Thus it is put under the influence of the acustic 

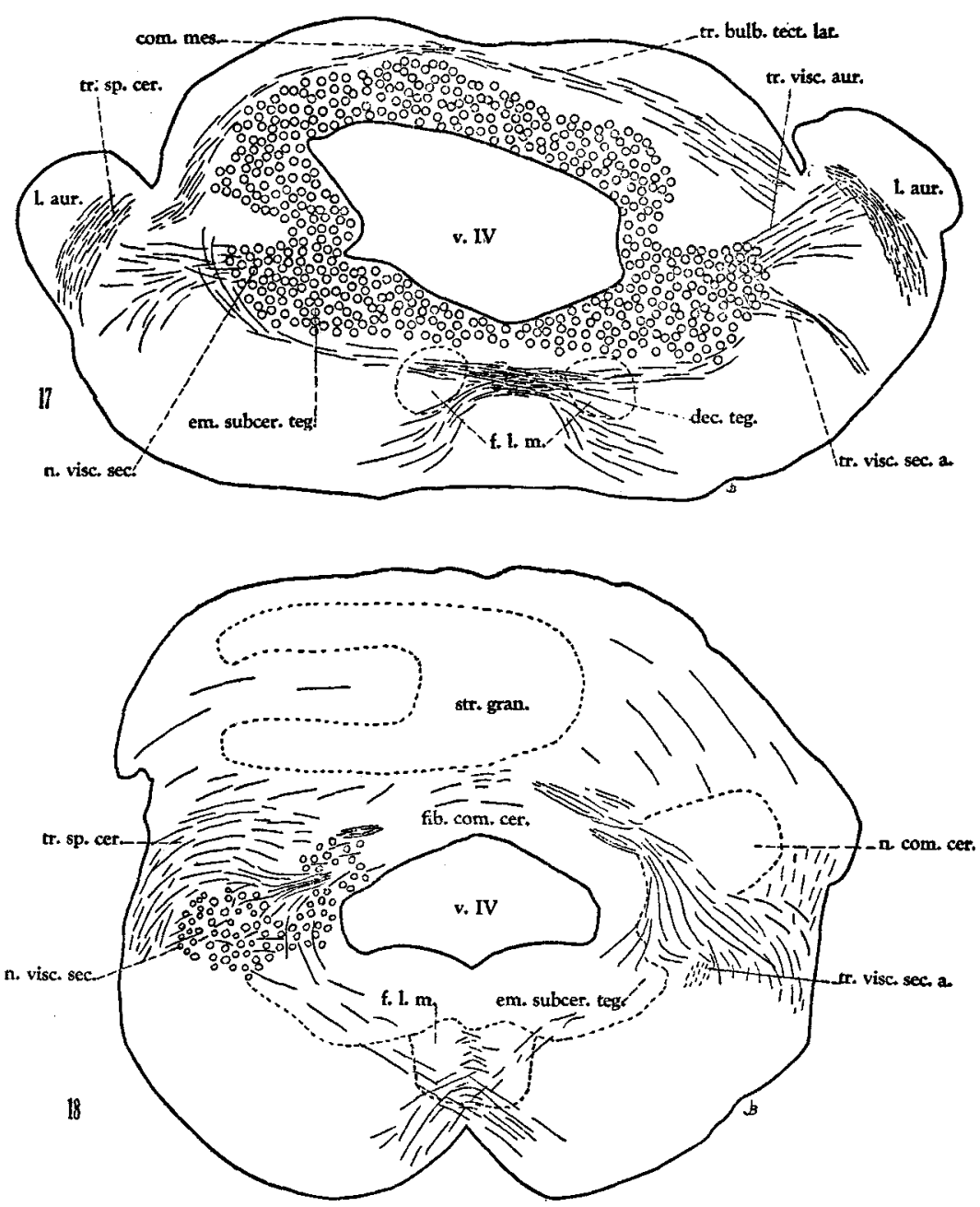

Fig. 17 A transverse section through the seecondary visceral lobe showing its connection with the auricular lobe. Necturus maculatus. Chrome silver. $\times 28$.

Fig. 18 A transverse section through the caudal portion of the secondary gustatory nucleus of Larsell. The left side is farther cephalad than the right. Rana catesbiana. Chrome silver. $\times 25$. 
area as well as under that of the trigeminal area and of the nucleus of the fasciculus solitarius. The connections from the nucleus of the fasciculus solitarius are very sparse, the position of the efferent facial nucleus obviously not being determined by such connections. The arcuates from the acustic and trigeminal areas of the opposite side also enter the nucleus. The dendrites of the efferent facial nucleus in both tailed and tailless forms are long and heavy, stretching ventrally and slightly laterally into the ventral field.

\section{Reptile (Anolis carolinensis)}

A. The nuclear groups

1. The nucleus of the fasciculus solitarius (fig. 19). Its cephalic end is at the level of entrance of the visceral afferent facial root. It consists of only a few small, lightly staining cells which are round to oval in shape. The cells are situated dorsal and lateral to the fasciculus solitarius, which at this point consists entirely of the descending visceral afferent facial root fibers. Only at levels somewhat caudal to the entrance of the facial nerve do a few cells appear on the medial aspect of the fasciculus solitarius.

At the level of entrance of the visceral afferent glossopharyngeal root (fig. 19) there appears a band of more deeply staining cells along the dorsal aspect of the fasciculus parallel to the ependyme of the fourth ventricle. Caudally the cells are more prominent and descending fibers of the fasciculus solitarius run up among them. At no point are the dorsal and lateral boundaries of the nucleus of the fasciculus solitarius definite. The cells of the nucleus intermingle with the cells of the vestibular nuclei which are just lateral.

At the level of the vagus nerve the nucleus is as described above, larger but even more indefinite as to exact boundaries. Caudally, the fasciculus solitarius moves dorsally along the lateral aspect of the cells of its nucleus, thereby helping to delimit it. At this level it acquires its greatest dorsoventral dimension, extending from the dorsal tip of the medulla oblongata down to the sulcus limitans. Toward the calamus 
scriptorius the nucleus shortens, its ventral portion disappearing and giving way to the efferent vagus nucleus.

These relations are similar to those described by Ariëns Kappers ('14) in the alligator and Varanus, although his forms had a somewhat greater development of the primary visceral afferent areas.

2. The mucleus of the inferior commissure of Haller. At the calamus scriptorius the two nuclei of the fasciculus solitarius meet each other at the midline to form the median nucleus of Ramón y Cajal. The cells, which are of the same generalized type as those comprising the nucleus of the fasciculus solitarius, are dorsal to the ventricle and just ventral to the somatic cells associated with the funicular area. The median nucleus continues caudally for a short distance and then fuses with the cells of the funicular area.

The caudal continuations of the nuclei of the fasciculus solitarius run back in the spinal cord region on each side of the midline for a short distance. The cells become incorporated in the dorsal horn gray and, while they may continue farther caudally, it is impossible to delimit them.

3. The secondary visceral nucleus (figs. 20,21). The caudal end of the nucleus is just cephalic to the forward end of the chief sensory trigeminal nucleus, and a short distance in from the periphery of the medulla oblongata (fig. 21). Medially this nucleus is continuous with the inner part of the nucleus isthmi but differentiated therefrom by its darker stain and greater compactness. The nucleus of the lateral lemniscus is ventral. Slightly more cephalically the secondary visceral nucleus spreads dorsomedially and forms a triangular mass of cells on the lateral aspect of the inner portion of the nucleus isthmi. The caudal end of the lateral part of the nucleus isthmi is just dorsal. The cephalic end of the secondary visceral nucleus is a round mass (fig. 20) wedged in between the ventrolateral tip of the medial part of the nucleus isthmi and the ventral tip of the lateral part of that same nucleus.

Shanklin ('30) described a secondary visceral nucleus in Chameleon vulgaris similar to that found in Anolis. Larsell 
('23, '24), who first described the nucleus in the frog, failed to find it in reptiles ('26, '32). This secondary visceral nucleus is much smaller in Anolis than in the frog and more in keeping with the size of the secondary ascending visceral tract.

4. The efferent facial nucleus. This nucleus appears to be slightly caudal to the level of entrance of the glossopharyngeal nerve, and in this fashion differs from the corresponding nucleus in Damonia (Black, '20), Boa, Varanus, Alligator, Chelone (Ariëns Kappers, '10), Eunectes, Chameleon and Testudo (de Lange, '16) which, in part at least, lies cephalic to the level of entrance of the glossopharyngeal nerve. In Anolis as in Damonia (Black, '20), the efferent facial nucleus is a cluster of cells placed ventromedially to the descending trigeminal root. Its cells are of the multipolar efferent type with somewhat irregularly shaped cell bodies.

\section{B. The root fibers}

1. The visceral afferent roots of the facial, glossopharyngeal and vagus nerves (fig. 19). The largest of the three roots is that of the facial nerve. Entering the medulla oblongata among the fibers of the acustic nerve, it pursues a medial and slightly ventral course to a point just dorsal to the sulcus limitans, where it turns sharply dorsally and caudally. There is no prefacial portion of the fasciculus solitarius, although a few fibers do turn cephalically as they approach the ventricle. These latter fibers end quite soon in the periventricular gray.

The smallest visceral afferent root is that of the glossopharyngeal nerve (fig. 19). It enters high on the lateral wall of the medulla oblongata and passes medially and slightly ventrally, through about the middle of the descending trigeminal root, to the fasciculus solitarius, where it turns caudally.

The visceral afferent vagus root enters through the ventral portion of the descending trigeminal root. It breaks up into several strands inside the medulla oblongata. These strands 
turn caudally in the fasciculus solitarius. Willard ('15) found essentially the same relations in his Anolis material.

2. The efferent facial root. The cells of the nucleus send their neuraxes dorsomedially to the dorsolateral surface of the medial longitudinal fasciculus where they turn cephalically. They retain this position as they course forward until at the level of the acustico-facial root complex they dip ventrally and caudally along the lateral aspect of the medial longitudinal fasciculus. They enter the arcuate system and turn directly laterally so that they pass out of the arcuate system and course just dorsal to the peripherally placed ventral efferent trigeminal nucleus. They emerge from the medulla oblongata dorsal to the descending trigeminal root and in the most ventral and caudal portion of the acusticofacial root complex.

The efferent facial nucleus of Anolis possesses the chief characteristics of this reptilian nuclear group. Ariëns Kappers ('10, '12) and Black ('20) presented charts showing reconstructions of this nucleus in various reptiles. With such charts the conditions in Anolis agree in so far as the efferent facial nucleus is related to the efferent glossopharyngeal nucleus so intimately that the two are inseparable. Anolis is found to have a more caudal extent for the ventral efferent trigeminal nucleus than the forms charted by the above observers, in that the efferent facial root touches the efferent trigeminal nucleus as its fibers course peripherally. Damonia, Boa and Varanus did not show this.

\section{The fiber connections}

1. The secondary connections of the nucleus of the fasciculus solitarius (fig. 19). From the ventral portion of the nucleus many small, finely medullated fibers run ventrolaterally to the region just ventromedial to the nucleus of the descending trigeminal root where they turn cephalically (fig. 19). More cephalically, at levels of the facial nerve and of the trigeminal nerve, this bundle is on the ventral aspect of the descending trigeminal root and its nucleus. As this latter root and its 
nucleus disappear from the field, the secondary ascending visceral tract moves dorsally and, for several sections, is lost among the many fibers of the region. A short distance cephalically what is tentatively assumed to be the tract enters the base of the secondary visceral nucleus (fig. 21). This connection is uncertain and demands further confirmation in other reptilian forms. Shanklin ('30), working with Weigert preparations of Chameleon, found a secondary visceral nucleus but not a secondary ascending visceral tract.

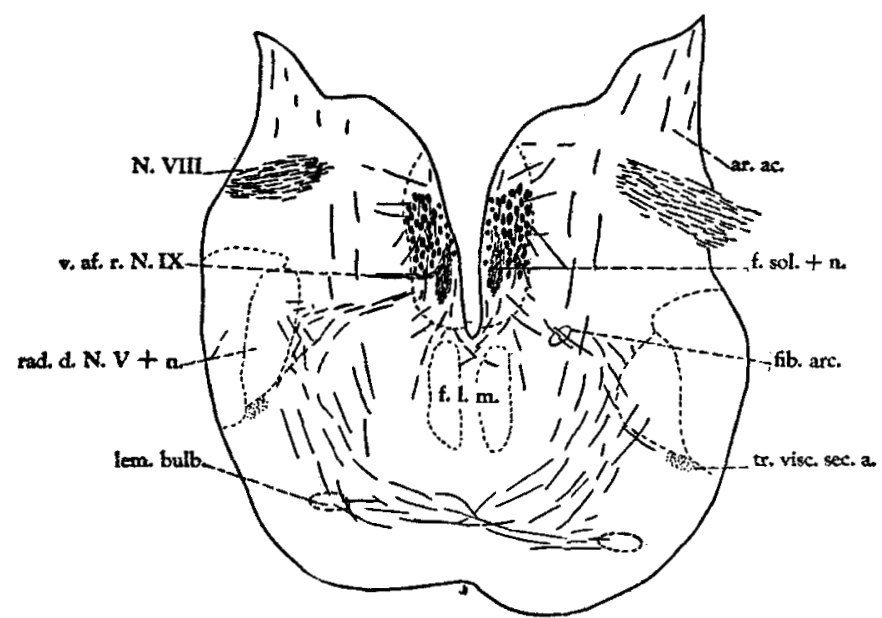

Fig. 19 A transverse section through the visceral afferent glossopharyngeal root. The dorsal portion of the section is more eephalad than is the ventral. Anolis carolinensis. Chrome silver. $\times 28$.

The arcuate system of the fasciculus solitarius is intimately related with the nucleus of the descending trigeminal root in that it passes close to its medial aspect as it courses to the midline (fig. 19). Fibers pass ventrolaterally from the nucleus of the fasciculus solitarius to the region of the nucleus of the descending trigeminal root, where they turn ventrally and then medially to run with the arcuates of this latter nucleus to the more ventral portion of the midline, to cross and course laterally to the contralateral bulbar (trigeminal) lemniscus, where they turn cephalically to pass to the mesencephalon and, 
presumably, to the diencephalon. The trigeminal or bulbar lemniscus is ventromedial to the descending trigeminal root and dorsolateral to the lateral lemniscus (fig. 19).

Running with the same fibers from the nucleus of the fasciculus solitarius are fascicles that pass to the efferent facial and glossopharyngeal nuclei. The dendrites of the nucleus of the fasciculus solitarius pass from the ventral portion of the nucleus ventrally and only slightly laterally to spread out among the reticular cells along the lateral aspect of the medial longitudinal fasciculus. On the lateral border of the nucleus of the fasciculus solitarius fibers pass to and from the vestibular area, and, at more caudal levels, distribute to the dorsal funicular region.

2. The inferior commissure of Haller. In Anolis the somatic and visceral commissures are very much intermingled. The fibers of the two fasciculi solitarii course dorsomedially to the midline above the central canal and cross in the ventral portion of the commissural region (fig. $14 \mathrm{f}$ ). No descending cervical bundles are found, the visceral commissural fibers being dissipated at the levels of their crossing in the funicular region and in the periventricular gray around the central canal.

3. The fiber connections of the secondary visceral nucleus (figs. 20,21). The secondary visceral nucleus lies in close relationship to the cerebellar commissure, being ventral to its lateral borders. Many small black fibers pass into the cerebellar commissure (fig. 21). Some of these fibers may be internuclear between the two secondary visceral nuclei as well as viscero-cerebellar in character.

The lemnisci systems are close to the medial aspect of the secondary visceral nucleus. Fibers are seen leaving the medial side of the nucleus and joining the dorsal fibers of the bulbar lemniscus with which they pass to the superior colliculus.

Shanklin ('30) described a large bundle to the medial longitudinal fasciculus. This connection is more poorly developed in Anolis. Fibers pass also to the trochlear nucleus without entering the medial longitudinal fasciculus (fig. 21). Shanklin 
('30) spoke of a connection to the hypothalamus. This connection, in Anolis, is very small and travels with cerebellohypothalamic fibers which pass through the secondary visceral nucleus.

Fibers leave the ventromedial aspect of the middle portion of the nucleus to pass to the tegmental area just lateral and
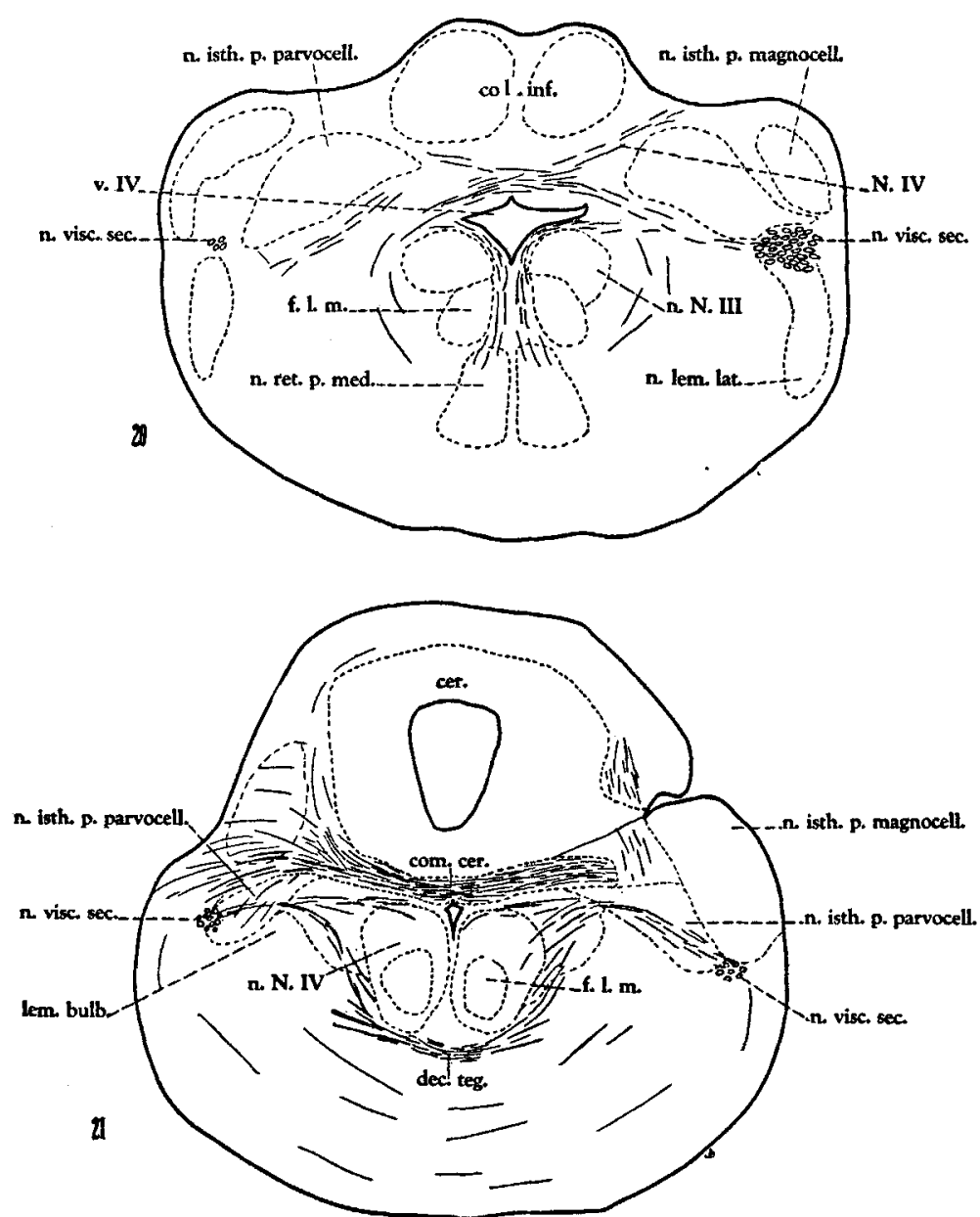

Fig. 20 A transverse section through the cephalie end of the secondary visceral nueleus. The left side of the section is farther cephalad than is the right side. Anolis carolinensis. Toluidin blue. $\times 28$.

Fig. 21 A transverse section through the caudal portion of the secondary visceral nucleus and its comnections. Anolis carolinensis. Chrome silver. $\times 28$. 
ventral to the medial longitudinal fasciculus. These crossed and uncrossed fibers join the most cephalic portion of the cerebello-tegmental tract. Those that cross do so just ventral to the decussation of the cerebello-tegmental fibers (dec.teg., fig. 21). Neither the tertiary visceral nucleus of Shanklin nor its connections can be found.

4. Fiber tracts entering the efferent facial nucleus. Part of the secondary fibers from the nucleus of the fasciculus solitarius that pass along the medial aspect of the nucleus of the descending trigeminal root pass by way of the latter to the small efferent facial nucleus. They are accompanied by fibers from the nucleus of the descending trigeminal root. The contralateral connections to the efferent facial nucleus pass it by way of the crossing fibers of the trigeminal lemniscus which include, as mentioned previously, fibers from the fasciculus solitarius. The closer proximity of the efferent facial nucleus to the periphery of the medulla oblongata is indicative of the influence of the large descending systems from the tectum.

\section{Bird (Columba domestica)}

A. The nuclear groups

1. The nucleus of the fasciculus solitarius (fig. 22). No visceral afferent gray can be found cephalic to the glossopharyngeal nerve, a fact in keeping with the extremely small size or possible non-existence of the visceral afferent component of the facial nerve. At the level of entrance of the glossopharyngeal nerve and caudally as far as the first rootlet of the vagus nerve there is no separate nucleus of the fasciculus solitarius. The cells associated with the fasciculus are among those of the ventromedial vestibular gray of the region and are situated in the ventrolateral corner of this latter nucleus.

At the level of entrance of the first vagus rootlet a patch of smaller and more darkly staining cells makes its appearance ventromedial to the fasciculus solitarius. At the level of entrance of the second vagus rootlet this nucleus of the fasciculus solitarius is quite large, having almost entirely replaced the periventricular gray of the region. It lies lateral

THE JOURNAL OF COMPARATTVE NEUROLOGY, VOL. 65 
to the efferent vagus nucleus and medial to the fasciculus solitarius (fig. 22). Of the periventricular gray only a small portion remains, just dorsal to the fasciculus solitarius. The nucleus is bounded dorsally by the ependyme of the fourth ventricle and ventrally by the longitudinal tracts of the ventral field. Near the calamus scriptorius the now smaller nucleus of the fasciculus solitarius moves dorsally and medially to cover the dorsomedial aspect of the efferent vagus nucleus.

2. The nucleus of the inferior commissure of Haller. At the calamus scriptorius the nucleus of the fasciculus solitarius joins its fellow, forming a continuous band of cells which caps the efferent vagus nucleus of each side. The median nucleus of Ramón y Cajal ('09) is formed of small granule cells and so is differentiable from the paired portion of the nucleus (fig. $14 \mathrm{~g}$ ). This median nucleus is triangular in shape, the apex of the triangle dipping ventrally between the efferent vagus cells of each side. The paired portion of the commissural nucleus becomes smaller, and finally merges insensibly with the surrounding gray. The median nucleus continues caudally into the spinal cord region as a constantly diminishing mass. On the whole, the nucleus of the inferior commissure is larger than that in any other form studied with the exception of the carp.

3. The efferent facial nucleus. Columba illustrates the typical avian pattern of the efferent facial nuclei as Ariëns Kappers ('10) previously had shown. The relations described by him are essentially those observed here. There are two nuclei, a dorsal and a ventral, which have approximately the same caudal limits; i.e., just cephalic to the level of entrance of the facial nerve. The dorsal nucleus is continuous at its cephalic tip with the dorsal efferent trigeminal nucleus. The ventral efferent facial nucleus extends more cephalically than does the dorsal nucleus. Ariëns Kappers ('10) found the cephalic limits of both efferent facial nuclei to be the same. Black ('22) found the typical avian pattern in Ciconia and Cacatua. Brandis (1894) was apparently in error in describing only one efferent facial nucleus for Columba. Craigie 
found only one efferent facial nucleus in the Kiwi ('30) but three in Chrysolampis and Chlorostilbon ('28).

B. The root fibers

1. The visceral afferent roots of the facial, glossopharyngeal and vagus nerves. The visceral afferent facial root cannot be found in the available material. It is either extremely small or else it is non-existent. This is in keeping with the results of Sanders ('29) for the dove and sparrow, of Craigie

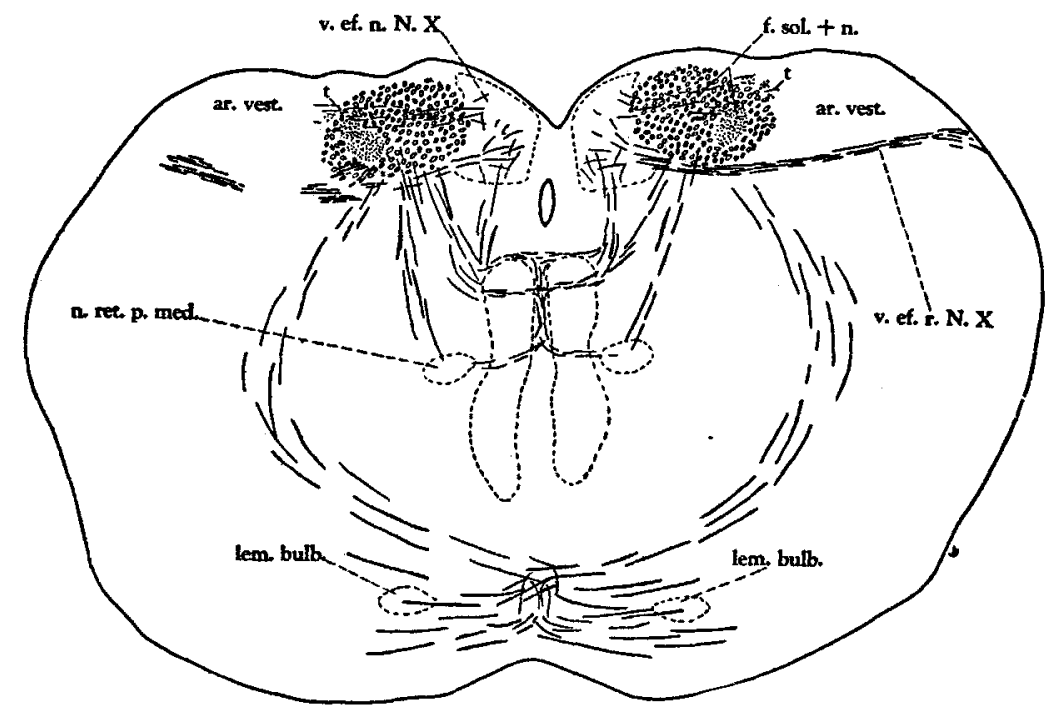

Fig. 22 A transverse section through the fasciculus solitarius caudal to the calamus seriptorius. Columba domestica. Chrome silver. $\times 14$.

('30) for the Kiwi, and of numerous other workers for many birds. Craigie ('28) found the humming bird to be an exception in that the visceral afferent root in this form is comparatively large. Bath ('06) found no taste buds on the tongues of all the birds he studied.

The visceral afferent glossopharyngeal root enters the lateral wall of the medulla oblongata just dorsal to the descending trigeminal root and ventral to the acustic root. The fibers course medially and then dorsally to a position among 
the arcuate fibers of the lateral lemniscus, just ventromedial to the magnocellular nucleus of the acustic complex. Here the fibers turn abruptly caudalward, forming the most cephalic portion of the fasciculus solitarius. At this level the latter contains at least 100 fibers.

The first visceral afferent vagus rootlet enters the medulla oblongata just dorsal to the descending trigeminal root. It courses medially and then dorsally to enter the fasciculus solitarius, wherein the fibers turn caudally. The rootlet is smaller than that of the glossopharyngeal nerve. The other visceral afferent vagus rootlets follow closely behind the first in rapid succession, there being ten or eleven in all. The rootlets all pass dorsal to, or through the dorsal portion of the descending trigeminal root. There is no evidence of crossing visceral afferent fibers such as Ramón y Cajal ('09) described. The fasciculus is largest in the midvagal region, where it is oval in shape with its long axis pointed dorsally and slightly laterally (fig. 22). Toward the calamus scriptorius the fasciculus becomes somewhat smaller and round in shape.

Many fibers of the fasciculus solitarius end among the cells of its nucleus. Others leave the dorsolateral aspect of the fasciculus and enter the descending vestibular tract wherein they appear to run to the calamus scriptorius to cross the midline (figs. 22, $14 \mathrm{~g}$ ). Ramón y Cajal ('09) divided the fasciculus solitarius into four parts in the 10-day chick. Addens ('34) did not find this grouping in the 7-day chick.

2. The efferent facial root. The root fibers of the ventral efferent facial nucleus course dorsocaudally and somewhat medially so as to pass through and around the dorsal efferent facial nucleus. They are joined by the neuraxes of this latter nucleus. The combined fibers pass farther dorsocaudally and also medially in loose strands. At a region just lateral to the upper fibers of the medial longitudinal fasciculus the strands turn abruptly lateralward and gather into a single large efferent facial root. The root emerges from the medulla oblongata just dorsal to the descending trigeminal root and cephalic and ventral to the acustic root complex. As typical 
of the less primitive birds, the efferent facial nuclei are definitely cephalic to the level of emergence of the facial root. Ariëns Kappers ('12) has pointed out the only known exception to this avian characteristic in the cassowary, a primitive type of bird.

Addens ('34) described crossing efferent facial root fibers in the 7-day chick. These cannot be found for the dove and the material suggests that possibly Addens might have mistaken vestibular for efferent facial fibers since the two are quite intermingled.

\section{The fiber connections}

1. The secondary connections of the nucleus of the fasciculus solitarius (fig. 22). At more cephalic levels, where the nucleus is merely a small undifferentiated mass surrounding the fasciculus, the connections are sparse and diffuse. At levels caudal to the first vagus rootlet the specialized nucleus of the fasciculus solitarius makes its appearance and the connections become much greater. The most of these latter are formed by the many fibers that pass to the posterior visceral efferent column of the same side. Other fibers pass in a sharp are to the midline where they cross between the more dorsal bundles of the medial longitudinal fasciculus and run to the visceral efferent cells of the opposite side (fig. 22). More caudalward this connection to the efferent glossopharyngeal and vagus nuclei includes the hypoglossal nucleus.

There are a few small internuclear fibers running between the nuclei of the fasciculus solitarius and of the descending vestibular root. Conduction is probably in both directions. Travelling with these are the great number of fibers of passage from the vestibular root area that are entering into the efferent vagus nuclei (fig. 22). A few other fibers connect the nucleus of the descending trigeminal root with the nucleus of the fasciculus solitarius. Longer fibers leave the nucleus of the fasciculus solitarius and run almost directly ventrally along the lateral aspect of the medial longitudinal fasciculus to terminate in the medial portion of the reticular nucleus. 
These viscero-reticular fibers may be crossed or uncrossed, those that cross doing so in the midline halfway between the dorsal and ventral surfaces, and running ventrally close to the median plane before turning laterally (fig. 22).

Running with these latter fibers are those that course farther ventrally along the midline before turning laterally. They run out laterally through the ventral portion of the medial part of the reticular nucleus and arch dorsalward to reach the area of the secondary ascending trigeminal lemniscus, which is just ventromedial to the descending trigeminal root. According to Sanders ('29) the secondary ascending bulbar (trigeminal) lemniscus ends partially in the area which Ariëns Kappers ('20) called the ventral part of the lateral mesencephalic nucleus, but she was not able to determine the complete termination of the tract. No intercalated nucleus of Staderini or nucleus parasolitarius can be found in the dove.

2. The inferior commissure of Haller (fig. $14 \mathrm{~g}$ ). The most cephalic fibers of the inferior commissure are chiefly from that part of the fasciculus solitarius that descends in the vestibular root. As these arch dorsal to the main body of the fasciculus solitarius, they are joined by a small fascicle from the main body of the fasciculus (fig. $14 \mathrm{~g}$ ). The combined bundle then crosses the midline dorsal to the body of the median nucleus of Ramón y Cajal ('09). Many fibers end in this latter nucleus while the rest form small descending bundles on each side of the midline very close to the dorsomedian sulcus. More caudally the main body of the fasciculus solitarius sends most of its fibers to cross in the midline. These are joined by the vestibular portion of the fasciculus solitarius. The fibers cross and are dissipated throughout the efferent vagus nucleus and the gray just above this latter nucleus. In the same manner the descending cervical bundles lose many of their fibers. The uncrossed portion of the fasciculus solitarius retains its lateral position until near the caudal end of the hypoglossal nucleus, where it moves medially, its fibers crossing the midline. The descending cervical bundles finally fade away somewhat caudal to the level where the dorsal horns of the spinal cord make their appearance. 
3. The tracts entering the efferent facial nucleus. The two efferent facial nuclei vary somewhat in their general appearance in that the dorsal is less compact than the ventral. The connections reflect the more generalized nature of the former nucleus by their greater vagueness. The dorsal nucleus receives no specialized innervation from any source but seems rather to receive fibers from all directions, probably most of which are trigeminal, cerebellar and vestibular in nature. Kosaka and Hiraiwa ('08) found that the neuraxes of this nucleus innervated the digastric muscle in the chicken. Ariëns Kappers ('10) and Black ('22) strongly stressed the trigeminal influence in the cephalic migration of the efferent facial nuclei. This is of interest since it has been found that the chief fiber connection of the ventral efferent facial nucleus seems to come from the superior vestibular nucleus and cerebellum. No definite connections with the chief sensory trigeminal nucleus are found. This latter may be due to too heavy impregnation.

\section{Mammal (Mus domesticus)}

\section{A. The nuclear groups}

1. The nucleus of the fasciculus solitarius (figs. 23, 24). The cephalic end of the nucleus is situated dorsomedial to the nucleus of the descending trigeminal root and ventral to the medial vestibular nucleus. The oval nucleus of the fasciculus is best delimited by the small size of its cells, which are from round to spindle-shaped in outline.

At levels of the glossopharyngeal and first vagus rootlets the nucleus is a large oval mass extending from the dorsal portion of the nucleus of the descending trigeminal root to a point about halfway to the midline. Its ventrolateral aspect is just dorsal to the nucleus parasolitarius.

In the midregion of the vagus nerve the nucleus of the fasciculus solitarius is divided by its fasciculus into two parts, a larger ventromedial and a smaller dorsolateral. The nucleus parasolitarius appears quite ventrolateral to the fasciculus and not closely associated with it. The dorsal efferent 
nucleus is situated ventromedial to the nucleus of the fasciculus solitarius.

More caudalward at the calamus scriptorius the fasciculus solitarius and its nucleus are pushed medially over the dorsal efferent nucleus. The ventromedial portion of the nucleus appears to be continuous with the nucleus intercalatus of Staderini, although this latter nucleus is very hard to delimit (fig. 23). It is very small and not in the typical position found by Winkler and Potter ('11) in the rabbit, between the dorsal

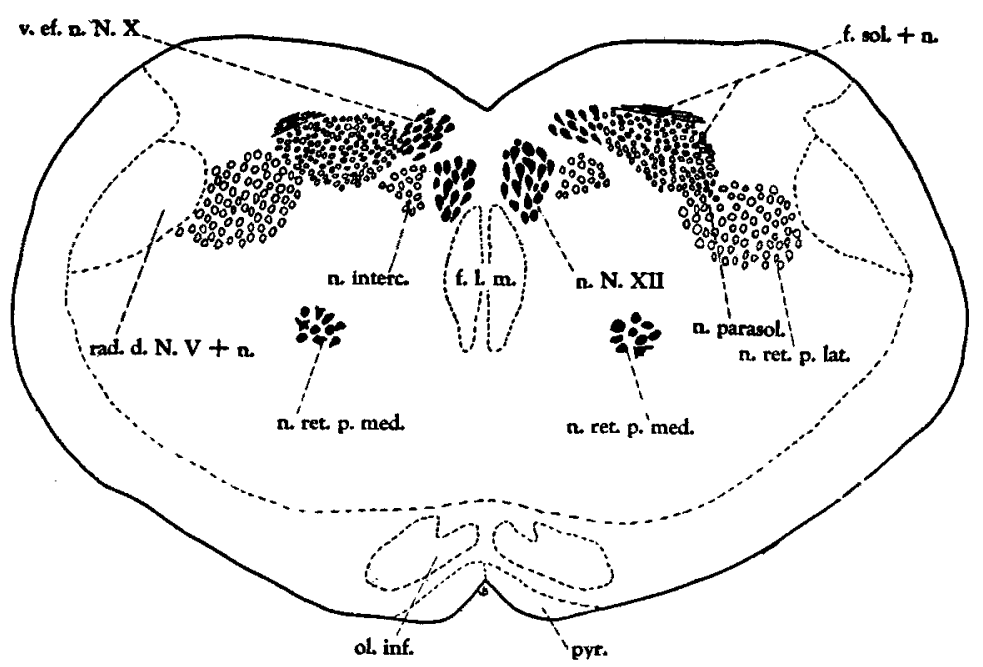

Fig. 23 A transverse section through the caudal part of the nucleus of the fasciculus solitarius showing the nucleus intercalatus of Allen. Mus domesticus. Toluidin blue. $\times 18$.

efferent nucleus and the hypoglossal nucleus, but pushed somewhat laterally. Allen ('23) found such a small intercalated nucleus of Staderini in the guinea pig and his interpretation is followed.

The nucleus parasolitarius appears to be continuous with the ventrolateral portion of the nucleus of the fasciculus solitarius at the levels of entrance of the glossopharyngeal and first vagus rootlets. Its cells are slightly larger than those of the nucleus of the fasciculus solitarius but somewhat smaller than the cells of the nucleus of the descending trigeminal root, 
which is just lateral to it. More caudalward, the nucleus parasolitarius shifts dorsomedially. Its boundaries become very uncertain, merging with reticular gray below, with the nucleus of the descending trigeminal root laterally and with the edge of the nucleus of the fasciculus solitarius dorsomedially (fig. 23). Allen ('27) spoke of the nucleus parasolitarius as the lateral portion of the reticular nucleus. Du Bois ('29) found essentially the same relations for the nucleus parasolitarius in the opossum as has been found in the mouse.

2. The nucleus of the inferior commissure of Haller. The nucleus of the fasciculus solitarius (fig. $14 \mathrm{~h}$ ) extends across the midline at a level slightly caudal to the calamus scriptorius. The cells are of the same size and shape as those around the fasciculus at more cephalic levels. The nucleus of the inferior commissure is very large and diffuse. It is continuous laterally with the caudal continuation of the nucleus of the fasciculus solitarius, the latter becoming quite small and disappearing as the spinal cord proper is approached (fig. $14 \mathrm{~h}$ ). The median nucleus of Ramón y Cajal fades out just cephalic to the dorsal commissure of the spinal cord.

3. The efferent facial nucleus. Ariëns Kappers ('10, '12) has described the typical position for the efferent facial nucleus in mammals as being caudal to the level of emergence of the efferent facial root. His description of the position of the nucleus in the rat is very similar to that found in the available mouse material. The nucleus is quite close to the periphery of the medulla oblongata.

The groupings of the different portions of the efferent facial nucleus were worked out for rodents by Marinesco (1898), van Gehuchten (1898), and Papez ('27). The groupings of the portions of the efferent facial nucleus in the mouse are similar to those found by Papez for the rat and for the guinea pig, although they have only approximately the same relations and sizes. Addens ('34) was of the opinion that a small nucleus dorsal to the body of the efferent facial nucleus was a salivary nucleus. In the mouse there are several clumps of cells in the area just dorsal to the main efferent facial nucleus which might be cells of such a nucleus. 
B. The root fibers

1. The visceral afferent roots of the facial, glossopharyngeal and vagus nerves (fig. 24). The visceral afferent facial root enters the medulla oblongata through the dorsal portion of the descending trigeminal root and somewhat ventral to the vestibular portion of the acustic nerve. It passes dorsomedially in several small fascicles to the area just medial to the dorsal tip of the descending trigeminal root, where it turns caudally to run back to the region of the glossopharyngeal nerve. Allen ('23) traced the root, in four fascicles, to a position similar to that found here. He found the degenerated facial fibers turned caudalward to extend only to the level of the first vagus rootlet, as van Gehuchten ('00 a) had found in the rabbit.

The visceral afferent glossopharyngeal root enters the medulla oblongata through the dorsal portion of the descending trigeminal root. It consists of two or three small fascicles which pass medially and dorsally to the fasciculus wherein they turn caudalward. The fasciculus, at this level, is more medially placed than at the level of entrance of the facial root.

The visceral afferent root pattern of the vagus nerve is rather complex and uncertain. The fibers pass, in comparatively large fascicles, through the dorsal half of the descending trigeminal root and then medially and dorsally to the fasciculus solitarius (fig. 24) as was reported by van Gehuchten ('00 a) for the rabbit, by Allen ('23) for the guinea pig and by Du Bois ('29) for the Virginian opossum.

As the fasciculus solitarius continues caudally it moves dorsomedially until, at the calamus seriptorius, it lies on the dorsolateral aspect of the dorsal efferent nucleus. In this position it enters the region of the inferior commissure. Van Gehuchten ('00 a) and Allen ('23) worked out the separate distribution of the facial, the glossopharyngeal and the vagus components of the fasciculus solitarius in the rabbit and in the guinea pig. The fibers of the fasciculus solitarius end in the nucleus of the fasciculus, although Allen ('23) found that they ended in the dorsal efferent vagus nucleus as well. 
2. The efferent root of the facial nerve. The root fibers leave the nucleus to move dorsomedially to a point just lateral to the most dorsal fibers of the medial longitudinal fasciculus. They turn sharply cephalically and form a compact bundle. At the level of entrance of the vestibular portion of the acustic nerve the root fibers dip sharply ventrolaterally and emerge from the medulla oblongata just ventral to the descending trigeminal root. Ariëns Kappers ('10) has discussed at some length the positions of the efferent facial nucleus and its root in mammals, including the rat. Nothing further can be added here concerning the neurobiotactic factors which give the nucleus its position in the mouse.

Addens ('34) summarized the literature relative to the possibility of crossing efferent facial root fibers. His contention was that there is crossing. The results of various workers lead to the conclusion that the crossing fibers come from cells which are situated dorsal to the main body of the nucleus and that they are of a secretory nature. In the mouse such a crossing probably takes place, although it is impossible to state from just what portion of the efferent facial nucleus the crossing fibers take their origin.

\section{The fiber connections}

1. The secondary connections of the nucleus of the fasciculus solitarius (fig. 24). The preglossopharyngeal portion of the nucleus of the fasciculus solitarius is comparatively small. Its connections are indistinct and diffuse in that the field is dominated by trigeminal, vestibular and acustic fibers. The arcuate fibers from the nucleus to the medial lemniscus, which Allen ('23 a) found in his chromatolysis work, cannot be differentiated here. There is evidence of a small connection with the efferent facial nucleus.

At the advent of the glossopharyngeal component to the fasciculus solitarius, the nucleus and its connections become quite large (figs. 23, 24). The nucleus is intimately related with the nucleus parasolitarius, this connection being predominately of finely medullated fibers which may account for 
Allen's ('23, '23 a) failure to find such a connection in Marchi preparations. Allen ('23) used the Marchi method after having made lesions in the nucleus of the fasciculus solitarius. $\mathrm{He}$ found medullated fibers coursing ventromedially in an arc to the medial lemniscus of the opposite side, where they turned cephalically to go to the ventral nucleus of the dorsal thalamus. He found no fibers in the mammillary peduncle but did find small flecks of material which he considered dirt.

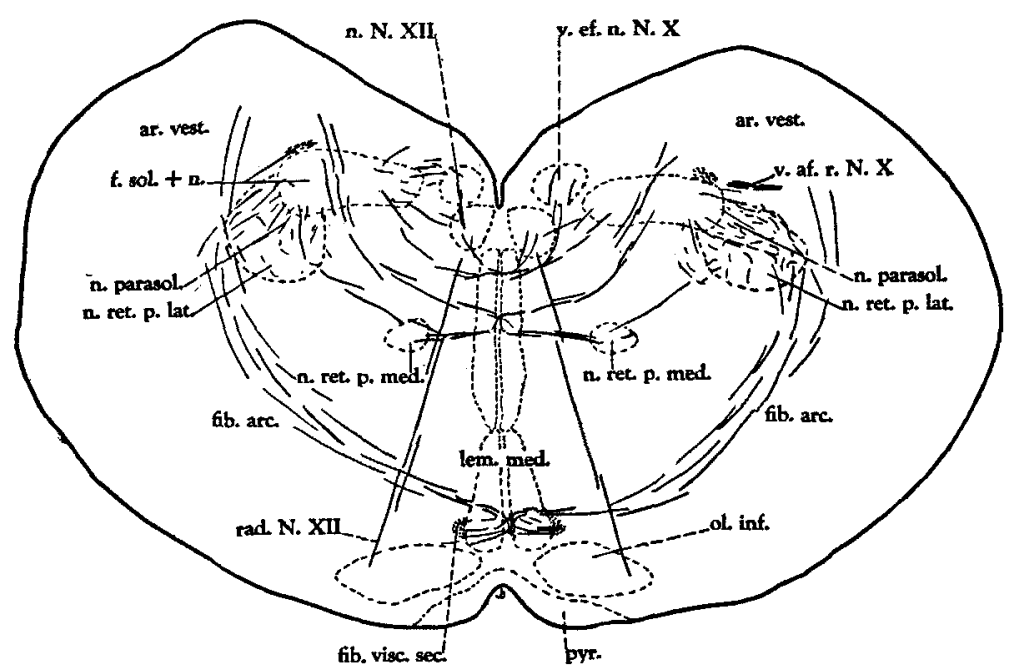

Fig. 24 A transverse section through the level of entrance of a vagal rootlet showing the nucleus of the fasciculus solitarius and its connections. Mus domesticus. Chrome silver. $\times 18$.

This matter might well be reinvestigated. Allen then attempted to control this evidence by cutting the medial lemniscus at the level of the inferior colliculus. He found chromatolysis of the cells in the cephalic half of the nucleus of the fasciculus solitarius. Unfortunately, the lesion was extremely large so that little or nothing concerning the pathway of the ascending impulses could be learned except that they were contralateral and not in the medial longitudinal fasciculus.

The mouse shows many arcuates which pass from the nucleus of the fasciculus solitarius to the region of the medial 
lemniscus of the opposite side of the field. They have a somewhat different course than do those found by Allen ('23 a) in the guinea pig. In the mouse the fibers leave the nucleus in a ventral and slightly lateral direction so that they pass through the nucleus parasolitarius (fig. 24). Some of them stop there, but many pass on through to go ventrally and medially in an are across the ventral portion of the midline. They turn cephalically on the lateral aspect of the medial lemniscus of the opposite side (fig. 24). The nucleus parasolitarius probably contributes to these areuates, agreeing with the work of Tumbelaka ('16) who found chromatolysis of these parasolitarius cells in a case of a tumor of the third ventricle. In the mouse these arcuates from the nucleus of the fasciculus solitarius and the nucleus parasolitarius exist in the region of the caudal vagus nerve rootlets, although in somewhat less abundance. Allen ('23 a) was of the opinion that they did not occur caudal to the cephalic rootlets of the vagus nerve in the guinea pig.

The possibility of a viscero-spinal tract is partially confirmed by the available material. There are many fibers which leave the caudal half of the nucleus of the fasciculus solitarius to pass to the nucleus parasolitarius and to the closely associated reticular gray. These allow for either a viscerospinal tract as found by Kosaka and Yagita ('05) for the dog and Hirose ('17) for the cat or for the viscero-reticular tract combined with the reticulo-spinal tract as found by Allen ('27) and Kohnstamm and Wolfstein ('07). Throughout all levels of the nucleus of the fasciculus solitarius there are homolateral and contralateral connections to the medial portion of the reticular nucleus (fig. 24). The contralateral fibers cross the middle portion of the midline so that they are quite distinct from the arcuates which pass forward to higher levels. At caudal levels the nucleus of the fasciculus solitarius sends many fibers medially to the efferent vagus nucleus, to the hypoglossal nucleus and to the region of the intercalated nucleus of Staderini, although this latter nucleus is extremely small in the mouse. The evidence for the mouse indicates 
that Staderini's nucleus is not associated particularly with the gustatory system, as Ariëns Kappers ('20) contended it was, since this latter system is normally developed in this form while the intercalated nucleus of Staderini is extremely small.

2. The inferior commissure of Haller (fig. $14 \mathrm{~h}$ ). At the level of the inferior commissure, the fasciculus solitarius sends almost its entire bulk toward the midline where the fibers cross, leaving only a very small uncrossed portion on each side just dorsolateral to the efferent vagus nucleus (fig. $14 \mathrm{~h}$ ). This rectus bundle continues caudalward until at some distance caudal to the level of the pyramidal decussation it is no longer differentiable from the surrounding fiber bundles. Many of the fibers of the visceral commissure end on the cells of the nucleus of the inferior commissure. No organized cervical bundles can be traced caudally. The fibers of the commissure appear to spread into the gray just lateral to the efferent vagus nucleus as well as into this latter nucleus. The smaller and more compact somatic commissure is caudal and slightly ventral to the visceral commissure although the two are not clearly delimited. The reticular area just lateral to the efferent vagus nucleus appears to be the chief correlation center between the visceral and the somatic elements of the inferior commissure.

3. The tracts entering the efferent facial nucleus. Ariëns Kappers ('10) has discussed the position of the efferent facial nucleus at some length. Nothing found here can be added to his discussion. The fibers entering the nucleus are from several regions. There are a great many that pass ventrally from the reticular gray above the efferent facial nucleus. The cortico-bulbar tract, which is just medial to the efferent facial nucleus, sends several crossed and uncrossed fibers to it, the latter type of fiber predominating. The nucleus of the fasciculus solitarius contributes only a few fibers, since it is quite small at the level of the efferent facial nucleus. 
SUMMARY OF DESCRIPTION

The foregoing study of the medulla oblongata in the various forms permits emphasis of the following points.

\section{Petromyzonts (Entosphenus, Ichthyomyzon)}

1) There is a relatively small development of the preglossopharyngeal visceral afferent column and its connections, which is associated with the relatively slight development of the visceral afferent facial root. 2) The inferior commissure of Haller is present. 3) In general the pattern of visceral afferent connections common to vertebrates has been established in these lowly forms. Further differentiation in passing toward higher forms represents specialization of certain portions of this system. 4) A generalized crossed bulbo-tectal connection is identifiable. 5) The efferent nucleus of the facial nerve is delimitable in accordance with the interpretation of Tretjakoff and Addens.

\section{Ganoid (Amia calva)}

1) The preglossopharyngeal visceral afferent area is well developed. A facial lobe, a glossopharyngeal lobe, and a vagal lobe are present. 2) The inferior commissure of Haller is differentiated into somatic and visceral portions. This descending visceral system is differentiated in Amia into the medial and lateral bundles described by Ramón y Cajal for teleosts and birds. 3) The secondary ascending gustatory tract with its nucleus of termination, the secondary gustatory nucleus, has made its appearance. Likewise a gustato-lobar system is demonstrable. 4) Somewhat better differentiated bulbo-tectal connections are obtainable in ganoids than in Petromyzonts. 5) The efferent facial nucleus is similar to that found by Droogleever Fortuyn and Theunissen.

\section{Teleosts (Salmo and Cyprinoides carpio)}

1) The visceral afferent centers and their connections are only moderately developed in the trout, showing only a slight 
improvement over the comparable centers and connections in Amia. In the carp these centers and connections are very large, with indication of marked specialization, although the basic arrangement is the same. The major difference in the secondary gustatory connections of the two forms is seen in the well-developed secondary descending gustatory tract demonstrable in the carp. 2) In the trout the inferior commissure of Haller is composed of approximately equal somatic and visceral components. The great development of gustatory fibers, gustatory centers, and secondary gustatory tracts in the carp, which is not balanced by a corresponding increase in the somatic afferent systems in this animal, is reflected in the relatively greater development of the visceral as compared with the somatic components of the inferior commissure. 3) The secondary gustatory nucleus has advanced from a primitive nucleus, forming a part of the periventricular gray, to a somewhat more discrete mass in the trout, and to a highly differentiated, easily recognized center with extensive connections in the carp. 4) There is a greater differentiation between the general bulbar lemniscus and the acustico-lateral lemniscus in the carp and the trout than in Amia, and a greater differentiation between the two systems in the carp than in the trout. 5) The efferent facial nucleus consists of a single group of cells in the trout and of two groups in the carp, the latter affording interesting confirmation of the theory of neurobiotaxis.

\section{Amphibians (Necturus, Amblystoma, Siren and Rana)}

1) As a group, amphibians are more generalized with respect to both the general and special visceral afferent systems than are either ganoids or teleosts but more specialized than are cyclostomes. The tailless forms show somewhat greater differentiation of these systems than do the tailed, but this parallels the progressive differentiation of the rest of the brain stem in these tailless forms. 2) The inferior commissure shows a low grade of differentiation in these animals, consonant probably with the decrease and, in adult tailless 
forms, with the absence of visceral afferent fibers from the gill region. 3) A secondary visceral tract and its nucleus have been identified in both tailless and tailed amphibians. They are representatives of the highly developed secondary gustatory nucleus and the secondary gustatory tract as found in the carp and in other fishes. 4) The primordial lemniscus in tailed amphibians approaches again the conditions found in petromyzonts, but shows a much greater degree of differentiation in the tailed forms. 5) The efferent facial nucleus shows the relations usually described for it in amphibians.

\section{Reptile (Anolis carolinensis)}

1) The visceral afferent system is poorly developed and poorly differentiated as compared with that in the fishes studied or in the mouse. 2) The inferior commissure of Haller is likewise small and relatively undifferentiated. 3) The identification of the secondary visceral tract and its nucleus is not beyond question. 4) The crossed secondary ascending systems to the mesencephalic regions are increased in the reptiles, an indication of the tendency toward cephalization in these forms, and of the importance of tectal levels here. 5) The efferent facial nucleus varies somewhat in position from that described for other reptiles (Ariëns Kappers, '10; de Lange, '16; Black, '20).

\section{Bird (Columba domestica)}

1) The very limited number of taste buds reduces the preglossopharyngeal fasciculus solitarius to such a degree that its identity is very uncertain, while secondary ascending tracts from visceral regions of the medulla oblongata to higher centers have not been identified. However, the general visceral afferent system shows a marked increase in these forms, with a corresponding increase in the postglossopharyngeal and postvagal fasciculus solitarius. 2) The inferior commissure of Haller is very large and well differentiated. Its size is comparable to that found in the carp and the mouse. 3) No 
secondary visceral tract with its associated nucleus has been identified. 4) The crossed secondary ascending tracts are found running from the nuclear gray associated with the fasciculus solitarius to the midbrain region, as in reptiles, and belp to illustrate the great importance of the mesencephalon in these forms. 5) The efferent facial nucleus follows the typical avian pattern.

\section{Mammal (Mus domesticus)}

1) Gustatory impulses are carried predominately by the facial and glossopharyngeal nerves, although such fibers are supplemented by gustatory fibers in the vagus nerve. In the mouse, the fasciculus solitarius is well developed throughout, as is its associated gray, this gray being particularly evident at the level of entrance of gustatory root fibers. The nucleus intercalatus is exceedingly small in the mouse, and it was not possible to trace to it any definite connection with entering root fibers of visceral efferent nerves, and its size shows no evident correlation with the relative development of the gustatory system in this form. 2) The inferior commissure of Haller is well developed, as is to be expected where there is a large general visceral efferent component. 3) No uncrossed secondary visceral tract and no secondary visceral nucleus are found. 4) The secondary ascending connections are by way of crossed bundles to the medial lemniscus with which they proceed forward to the isthmus region. To what extent these visceral fibers may accompany the medial lemniscus forward from this level to the dorsal thalamus and to what extent they may reach the hypothalamus by way of the mammillary peduncle has not been determined, although the latter course, for at least a part of the fibers, seem probable. A bulbospinal or reticulo-spinal path, arising from the reticular gray in the region of the fasciculus solitarius, and supplemented perhaps by fibers from the nucleus parasolitarius, provides a discharge path for visceral impulses for motor and possibly preganglionic centers of the cord, the connection between the reticular gray in question and the nuclear gray of the fasciculus solitarius being provided for by internuclear fibers. The 
efferent facial nucleus is large and highly specialized in the mouse. Its position is typical. The presence of crossed efferent facial root fibers (probably salivary) is suggested by the available material.

\section{DISCUSSION}

The changes of structure of the primary centers for visceral afferent impulses in the medulla oblongata reflect the phylogenetic increase and decrease in their importance. Thus, while there is no definite cellular organization of the visceral afferent centers in petromyzonts, Amia does show a tendeney toward the higher differentiation which is represented in the corticoid lamination as found in the trout and which reaches its greatest development in highly gustatory teleosts such as the carp. Reverting to a point closer to the main line of descent, the urodeles show a primitive condition of the primary visceral afferent centers which is but slightly better than that for petromyzonts. Anura and reptiles show but little advance from the urodele condition. However, in birds and mammals there is some increase in the importance of the primary visceral afferent centers, this increase in birds being confined to the more caudal portions of the medulla oblongata, whereas in mammals it extends forward to the more cephalic regions as well. These differences in the systems in birds and mammals are instructive when correlated with the relative development of the general visceral afferent and the special visceral afferent components in the two forms and are considered after a review of the gustatory mechanisms in lower forms.

Ganoids and teleosts are forms with highly developed gustatory mechanisms, a condition which reaches its peak in fishes such as the carp. All of these fishes have developed a secondary gustatory nucleus for relaying gustatory impulses to the hypothalamus and to the cerebellum. Again, in amphibians, and perhaps in reptiles, there is a specialized secondary nucleus for uncrossed fibers from the primary centers. All of these latter vertebrate groups have moderately developed gustatory mechanisms, agreeing with their poorly differentiated secondary visceral nucleus. It is significant that the 
bird, which has a very small number of taste buds and a correspondingly small gustatory apparatus, is the first form found to possess no secondary visceral nucleus, making it probable that the secondary visceral nucleus of amphibians is in reality a secondary gustatory nucleus and a relatively exact homologue of that nucleus in fishes, although more generalized in structure and connections, a change which is to be expected with their smaller gustatory equipment. All of this is a reflection of the mode of living of the various forms. Taste is of more importance to aquatic animals whose medium of support is also a carrier of gustatory stimuli. Amphibians and reptiles are only partially aquatic and the gustatory system fights a losing battle with the other sensory systems which develop greatly under the conditions arising in a terrestrial mode of living. In birds the sense of balance and sight and touch become highly developed, the gustatory system becoming minimal. As a part of this great reduction in the gustatory system the secondary visceral or gustatory nucleus and its connections are dropped out.

Taste, however, does increase again in the mammalian stem, although in a divergent manner. Mammals, most of which are terrestrial, show greater cephalization, and, in certain of them, with their restless modes of exploration, taste has become highly differentiated. These facts are reflected in many of the structures of the mammalian central nervous system. In all forms studied, including the lowly cyclostomes, a part of the general pattern of the visceral afferent centers is a projection forward of impulses, by crossed fibers, to the tectum. This is found to exist up to and including birds. In mammals taste is carried forward by a crossed connection directly to the diencephalon, probably to the dorsal thalamus and certainly to the tuber cinereum, instead of terminating in the tectum and being carried from there by an additional neuron to the thalamus and the hypothalamus. This dropping out of a synapse in the path to higher centers is a part of the general process of greater cephalization. 
The general visceral afferent system, because of its association with most of the vagus nerve and a part of the glossopharyngeal nerve, is confined to the more caudal portion of the medulla oblongata. In teleosts, and especially in the carp, there is a very large gustatory component in the caudal portion of the medulla oblongata so that the general visceral afferent system is masked by it. In other forms, however, such as cyclostomes, amphibians, reptiles, birds and mammals, the development of the caudal portion of the visceral afferent system of the medulla oblongata may be considered an index of the amount of general visceral afferent impulses which reach the central nervous system. It is a striking fact that this portion of the system, with the inferior commissure of Haller included, shows a great advance in development in birds and in mammals. This advance is coexistent with a considerable increase in the size and the complexity of the laryngeal regions and the digestive tube as compared with these structures in reptilian and subreptilian formsin short, a larger visceral afferent system is needed to control the movements and secretions of a more complex digestive system and larynx. This control is effected by means of the efferent vagus nucleus and by the preganglionic fibers of the spinal cord region, the latter being under the control of the visceral afferent system of the medulla oblongata through reticulo-spinal fibers and possibly other connections by way of the inferior commissure.

The variations in position of the efferent facial nucleus, throughout the series of vertebrates studied, have been emphasized and the details of these do not require repetition here. The shifts in position of this nuclear group offer one of the most useful series of facts for the confirmation of Ariëns Kappers' theory of neurobiotaxis. He used it so frequently to illustrate this theory, that any further discussion of it is bound to be reiteration.

A phylogenetic study of the type here undertaken serves chiefly to emphasize the necessary and invariable relations existing between structure and function. The rise or fall of 
any special system is directly correlated with the change in the behavior of the animal, frequently with changes in its general manner of living. The elaboration of such special systems-whether they be gustatory, auditory, visual or of some other type-affects the differentiation of many other parts of the nervous system and results in a correlated development. This reaches its highest expression in mammals with the projection of impulses from receptive centers of the brain stem on diencephalic areas, providing for the correlated development of these areas and of the sensory areas of the cortex.

\section{LITERATURE CITED}

ADDENS, J. L. 1933 The motor nuclei and roots of the cranial and first spinal nerves of vertebrates. Zeits. f. Anat. u. Entwicklungsgesch., I. Abteil. d. Zeitschr. f. ges. Anat., Bd. 101, S. 307.

1934 A critical review of the occurrence of crossing root fibers in facialis, vestibular, glossopharyngeal and vagus nerves. Psychiat. en neurol. Bl., p. 274.

ALLEN, W. F. 1923 Orlgin and distribution of the tractus solitarius in the guinea pig. J. Comp. Neur., vol. 35, p. 171.

1923 a Origin and destination of the secondary visceral fibers in the guinea pig. J. Comp. Neur., vol. 35, p. 275.

1927 Experimental-anatomical studies on the visceral bulbospinal pathway in the cat and guinea-pig. J. Comp. Neur., vol. 42, p. 393.

ARUËNS KAPPERS, C. U. 1908 Weitere Mitteilungen über Neurobiotaxis. II. Die phylogenetische Entwicklung des horizontalen Schenkels des Facialwurzelknies. Folia Neuro-biol., Bd. 2, S. 255.

1910 Idem. V. The migrations of the motor cells of the bulbar trigeminus, abducens and facialis in the series of vertebrates and differences in the course of their root-fibers. Verhandl. d. Kon. Akad. v. Wetensch. te Amsterdam, Tweede Sectie, vol. 16, p. 1.

1912 Idem. VII. Die phylogenetische Entwicklung der motorischen Wurzelkerne in Oblongata und Mittelhirn. Folia Neuro-biol., Bd. 6, Sommer-Ergänzungs-Heft, s. l.

1914 Der Geschmack perifer und central. Zugleich eine Skizze der phylogenetischen Veränderungen in den sensibelen VII, IX und $X$ Wurzeln. Psychiat. en neurol. Bl., Bd. 18, \$. 82.

1920 Vergleichende Anatomie des Nervensystems. Haarlem, E. F. Bohn.

ARIËNS KAPPERS, C. U. AND E. HAMMer 1918 Das Zentralnervensystem des Oehsenfrosehes (Rana eatesbyana). Psychiat. en neurol. Bl., Bd. 22, S. 368.

Ariëns Kappers, C. U., G. Carl Huber and E. C. Crosby 1936 The comparative anatomy of the nervous system of vertebrates ineluding man. New York, The Macmillan Company. 
BATH, W. 1906 Die Geschmackorgane der Vögel und Krokodile. Arch. $f$. Biontol., Bd. 6, S. 1.

Berkelbach vaN Der Sprenkel, H. 1915 The central relations of the cranial nerves in Siluris glanis and Mormyrus cashive. J. Comp. Neur., vol. 25, p. 5.

Black, D. 1917 The motor nuclei of the cerebral nerves in phylogeny: A study of the phenomena of neurobiotaxis. I. Cyclostomi and Pisces. $J$. Comp. Neur., vol. 27, p. 467.

1917 a Idem. II. Amphibia. J. Comp. Neur., vol. 28, p. 379.

1920 Idem. III. Reptilia. J. Comp. Neur., vol. 32, p. 61. 1922 Idem. IV. Aves. J. Comp. Neur., vol. 34, p. 233.

BoK, S. T. 1915 Die Entwicklung der Hirnnerven und ihrer zentralen Bahnen. Die stimulogene Fibrillation. Folio Neuro-biol., Bd. 9, \$. 475.

BRANDIS, F. 1894 Untersuchungen über das Gehirn der Vögel. II. Theil: Ursprung der Nerven der Medulla Oblongata. III. Acusticusgruppe. Arch. f. mikr. Anat., Bd. 43, S. 96.

BRIckNBR, R. M. 1929 A description and interpretation of certain parts of the teleostean midbrain and thalamus. J. Comp. Neur., vol. 47, p. 225.

1930 A new tract in Herrick's gustatory system in certain teleosts. J. Comp. Neur., vol. 50, p. 153.

BURR, H. S. 1928 The central nervous system of Orthagoriscus mola. J. Comp. Neur., vol. 45, p. 33.

Carrater, J. 1926 A general survey of the forebrain of Sphenodon. J. Comp. Neur., vol. 42 , p. 255 .

CoRDs, E. 1929 Die Kopfnerven der Petromyzonten. (Untersuchungen an Petromyzon marinus). Zeits. f. Anat. u. Entwicklungsgesch., Bd. 89, S. 201.

CRaigle, E. H. 1928 Observations on the brain of the humming bird (Chrysolampis mosquitus Linn. and Chlorostilbon caribaeus Lawr.). J. Comp. Neur., vol. 45, p. 377.

1930 The brain of the kiwi (Apteryx australis). J. Comp. Neur., vol. 49 , p. 223.

Drooglegver ForTUYN, A. B. 1912 Notiz über den Eintritt der motorischen Nervenwurzeln in die Medulla Oblongata und über die Lage der motorischen Kerne bei Amia calva L. Folia Neuro-biol., Bd. 6, S. 27.

DuBors, F. S. 1929 The tractus solitarius and attendant nuclei in the Virginian opossum (Didelphis virginiana). J. Comp. Neur., vol. 47, p. 189.

Edinger, L. 1908 Vorlesungen über den Bau der nervösen Centralorgane des Menschen und der Thiere. Ireipzig, F. C. W. Vogel.

Gendohten, A. van 1898 Researches sur l'origine réele des nerfs craniens. II. Le nerf facial. J. de Neurol., vol. 3, p. 273.

1900 Recherches sur la terminaison centrale des nerfs sensibiles périphériques. I. Le nerf intermediaire de Wrisberg. Le Névraxe, rol. 1, p. 5 .

1900 a Idem. II. Le faiscean solitaire. Le Névraxe, vol. 1, p. 173.

HERRICK, C. J. 1905 The central gustatory paths in the brains of bony fishes. J. Comp. Neur., vol. 15, p. 375.

1906 On the centers for taste and touch in the medulla oblongata of fishes. J. Comp. Neur., vol. 16, p. 403. 
HerRick, C. J. 1907 A study of the vagal lobes and funicular nuclei of the brain of the codfish. J. Comp. Neur., vol. 17, p. 67.

1908 On the commissura infima and its nuclei in the brains of fishes. J. Comp. Neur., vol. 18, p. 409.

1914 The medulla oblongata of larval Amblystoma. J. Comp. Neur., vol. 24, p. 343 .

1917 The internal structure of the midbrain and thalamus of Necturus. J. Comp. Neur., vol. 28, p. 215.

1930 The medulla oblongata of Necturus. J. Comp. Neur., vol. 50, p. 1.

Hirose, K. 1917 Ueber eine bulbospinale Bahn. Folia Neuro-biol., Bd. 10, S. 371.

Hocke Hoogenboom, K. J. 1929 Das Gehirn von Polyodon folium Lacep. Jahrb. f. Morph. u. mikr. Anat., Abt. 2, Zeits. f. mikr. Anat. Forschung, Bd. $18, \mathrm{~B}, 311$.

Holmgren, N. AND C. J. vaN DER Horst 1925 Contribution to the morphology of the brain of Ceratodus. Acta Zool., Bd. 6, S. 59.

HoRst, C. J. VAN DER 1918 Die motorischen Kerne und Bahnen in dem Gehirn der Fische, ihr taxonomischer Wert und ihre neurobiotaktische Bedeutung. Tijdsehr. d. Ned. Dierk. Vereen., vol. 16, p. 168.

HUBER, G. CARL 1927 New method of fixation and staining of the central nervous system for purpose of study of cytoarchitecture. Contributions to Medical Science, Aldred Scott Warthin anniversary volume, p. 1, Ann Arbor, Wahr.

Huber, G. CARL AND E. C. CrosbX 1926 On thalamic and tectal nuclei and fiber paths in the brain of the American alligator. J. Comp. Neur., vol. 40, p. 97.

Huber, G. CARL AND S. R. GUild 1913 Observations on the peripheral distribution of the nervus terminalis in Mammalia. Anat. Rec., vol. 7, p. 253.

Jansen, J. 1930 The brain of Myxine glutinosa. J. Comp. Neur,, vol. 49, p. 359 .

Johnston, J. B. 1901 Brain of Acipenser. A contribution to the morphology of the vertebrate brain. Zool. Jahrb., Abt. f. Anat. u. Ontog., Bd. 15, S. 59 .

1902 The brain of Petromyzon. J. Comp. Neur., vol. 12, p. 1.

1905 The cranial nerve components of Petromyzon. Morph. Jahrb., Bd. 34, S. 149 .

1908 Additional notes on the eranial nerves of petromyzonts. J. Comp. Neur., vol. 18, p. 569.

1910 A comment upon recent contributions on the brain of petromyzonts. Anat. Anz., Bd. 37, S. 153 and S. 182.

KAIDA, Y. 1929 Ueber den Ursprung und den peripheren Verlauf der sogenannten zentrifugalen Vestibularismerven nach Leidler (Fasciculus vestibularis medialis nach Kaplan). Arch. f. Ohren, Nasen und Kehlkopfh., Bd. 123, S. 62.

KingsBury, B. F. 1895 On the brain of Necturus maculatus. J. Comp. Neur., vol. 5, p. 139 . 
Koнnstam , O. 1902 Vom Centrum der Speichelsekretion, dem Nervus intermedius und der gekreuzten Facialiswurzel. Verh. Congr. innere Medizin. Congr. 20, s. 361.

KoHNstamm, O. AND Hindfacang 1910 Der Nucleus intermedius sensibilis als Ursprung einer gekreuzt aufsteigenenden Bahn (Viszeral Bahnq). Neurol. Centralbl., Bd. 29, S. 663.

KoHNSTAMM, O. AND J. Wolfrstein 1907 Versuch einer physiologischen Anatomie der Vagusursprünge und des Kopfsympathetieus. J. f. Psychol. u. Neurol., Bd. 8, s. 177.

KosaKa, K. AND K. HrRaIwa 1908 Ueber die Facialiskerne des Huhnes. Jahrb. f. Psychiat. u. Neurol., Bd. 25, s. 57.

KosaKA, K. AND K. YAGITA 1905 Experimentelle Untersuchungen über den Ursprung des N. Vagus und die centralen Endigung der dem Plexus nodosus entstammenden sensibilen Vagusfasern, sowie über den Verlauf ihrer secundären Bahn. Shinkeigaku Zasshi, Tokyo, Bd. 4, 8. 29.

KRAUSE, R. 1923 Mikroseopische Anatomie der Wirbeltiere in Einzeldarstellungen. IV. Teleostier, Plagiostomen, Zyklostomen und Leptokardier. P. 788, Berlin and Leipzig, W. de Gruyter and Co.

KREnT, H. 1930 Ueber die Faserzüge im Zentralnervensystem von Salamandra maculosa Laur. Jahrb. f. Morph. u. mikr. Anat., Bd. 23, S. 239.

1931 Ueber die Faserzüge im Zentralnervensystem von Proteus anguineus Laur. Jahrb. f. Morph. u. mikr. Anat., Bd. 25, \$. 376.

LANGe, S. J. DE 1916 Das Hinterhirn, das Nachhirn und Rüekenmark der Reptilien. Folia Neurol-biol., Bd. 9, S. 385.

LarsmLL, O. 1923 The cerebellum of the frog. J. Comp. Neur., vol, 36, p. 89. 1924 The nucleus isthmi of the frog. J. Comp. Neur., vol. 36, p. 309. 1926 The cerebellum of reptiles: lizards and snake. J. Comp. Neur., vol. 41, p. 59.

1932 The cerebellum of reptiles: chelonians and alligator. J. Comp. Neur., vol. 56, p. 299.

Marinesco, G. 1898 I'Origine du facial supérieur. Rev. neurol, vol. 6, p. 30. La presse méd., vol. 9, p. 85, 1899.

Mayser, P. 1882 Vergleichend anatomische Studien über das Gehirn der Knochenfische mit besonderer Berücksichtigung der Cyprinoiden. Zeitschr. f. wiss. Zool., Bd. 36, S. 259.

NorRIs, H. W. 1913 The cranial nerves of Siren lacertina. J. Morph., vol. 24, p. 245.

OsBoRN, H, F. 1888 A contribution to the internal structure of the amphibian brain. J. Morph., vol. 2, p. 51.

PAPEz, J. W. 1927 Subdivisions of the facial nucleus. J. Comp. Neur., vol. 43, p. 159.

RAḾ́N Y CAJAL, S. 1909 Contribución al estudio de los ganglios de la substancia reticular del bulbo con algunos detalles concernientes á los focos motores y rias reflejas bulbares y mesocefálicas. Trab. d. lab. de invest. biol., Univ. de Madrid, vol. 7, p. 259.

RöTHIG, P. 1913 Contributions upon neurobiotaxis. (The arrangement of the motor nuclei in Myxine glutinosa, in Cryptobranchus, Necturus, Rana fusea and Bufo). Kon. Akad. v. Wetensch. te Amsterdam, Proc. sect. sc., vol. 16, p. 296. 
RöTHIG, P. 1927 Beiträge zum Studium des Zentralnervensystems der Wirbeltiere. II. Ueber die Faserzüge im Mittelhirn, und in der Medulla Oblongata der Urodelen und Anuren. Zeits. f. mikr. Anat. Forsehung, Bd. 10, S. 381 .

RöThig, P. AND C. U. ARIËNs Kappers 1914 Further contributions to our knowledge of the brain of Myxine glutinosa. Kon. Akad. v. Wetensch. te Amsterdam, Proc. sect. se., vol. 17, p. 2.

SarTo, T. 1928 Ueber die Müllerschen Zellen in Gehirn des japonischen Flussneunauges. Folia anat. Japon., vol. 6, p. 457.

SANDERS, E. B. 1929 A consideration of certain bulbar, midbrain, and cerebellar centers and fiber tracts in birds. J. Comp. Neur., vol. 49, p. 155.

SHANKLIN, W. M. 1930 The central nervous system of Chameleon vulgaris. Acta Zool., Bd. 11, S. 425.

Shilling, K. 1907 Ueber das Gehirn von Petromyzon fluviatilis. Abhandl. d. Senckenb. nat. Gesellsch. Frankfort am Main, Bd. 30, S. 423.

Tello, F. 1909 Contribución al conocimiento del encéphalo de los teléssteos. Los núcleos bulbares. Trab. d. lab. de invest. biol., Univ. de Madrid, vol. 7, p. 1 .

Theunisser, F. 1914 The arrangement of the motor roots and nuclei in the brain of Acipenser ruthenus and Lepidosteus osseus. Kon. Akad. v. Wetensch. te Amsterdam, Proc. sect. sc., vol. 16, p. 1032.

Tretjakom, D. 1909 Das Nervensystem von Ammocoetes. Ir. Gehirn. Arch. f. mikr. Anat., Bd. 74, S. 636 .

1927 Das periphere Nervensystem des Flussneunauges. Zeits. $f$. wiss. Zool., Bd. 129, S. 359 .

TumbFinkA, R. 1916 Konsekutive Veränderungen eines kleinen Herdes in dem ventrolateralen Thalamuskern und das demselben zugrunde liegende klinische Bild. Psychiat. en neurol. Bl., Bd. 20, S. 377.

Wallenkerg, A. 1899 Notiz über einen Sehleifenursprung des Pedunculus corporis mamillaris beim Kaninchen. Anat. Anz,, Bd. 16, S. 156. 1907 Die kaudale Endigung des bulbo-spinalen Wurzeln des Trigeminus, Vestibularis und Vagus beim Frosch. Anat. Anz., Bd. 30, S. 564 .

WILlakd, W. A. 1915 The cranial nerves of Anolis carolinensis. Bull. Mus. Comp. Zool. Harvard, vol. 59, p. 15.

Windie, W. F. 1933 Neurofibrillar development in the central nervous system of. cat embryos between 8 and $12 \mathrm{~mm}$. long. J. Comp. Neur., vol. 58, p. 643 .

Winkler, C. AND A. Potper 1911 An anatomical guide to experimental researches on the rabbit's brain. Amsterdam, Versluys.

YaGiTA, K. AND S. HAYAMA 1909 Ueber das Speichelsekretioncentrum. Neurol. Centralbl., Ba. 28, s. 738. 